\title{
Cyclin D3-CDK6 Complex Facilitates Tumorigenesis by Regulating the C-Myc/miR-15a/16 Axis in a Feedback Loop in Gastric Cancer
}

Yeting Hong ( $\sim$ hongyeting123@163.com )

College of Laboratory Medicine, Hangzhou Medical College, Hangzhou, 310053, China. Zhejiang

Provincial People's Hospital, People's Hospital of Hangzhou Medical College, Hangzhou, 310014, China

Wei He

Anhui Medical University

Jianbin Zhang

Hangzhou Medical College

Lu Shen

Wenzhou Medical University

Chong Yu

Hangzhou Medical College

Liang Yan

Wannan Medical College

Hanxiao Chen

Wenzhou Medical University

Yanqian Wu

Hangzhou Medical college

Linjie Chen

Hangzhou Medical college

Jianxin Lyu

Hangzhou Medical College

Liu Yang

Hangzhou Medical college

\section{Research}

Keywords: Cyclin D3-CDK6 complex, miR-15a/16, gastric cancer, cell proliferation, cell cycle progression

Posted Date: December 14th, 2020

DOI: https://doi.org/10.21203/rs.3.rs-125333/v1 
License: (c) (i) This work is licensed under a Creative Commons Attribution 4.0 International License. Read Full License 


\section{Abstract}

Background: Cyclin D3-CDK6 complex is a component of the core cell cycle machinery that regulates cell proliferation. By using Human Protein Atlas database, a higher expression level of this complex was found in gastric cancer. However, the function of this complex in gastric cancer remain poorly understood. This study aims to determine the expression pattern of this complex in gastric cancer and to investigate its biological role during tumorigenesis.

Methods: To demonstrate that Cyclin D3-CDK6 regulate the c-Myc/miR-15a/16 axis in a feedback loop in gastric cancer, a series of methods were conducted both in vitro and in vivo experiments, including qRTPCR, western blot analysis, EdU assay, flow cytometry, luciferase reporter assay and immunohistochemical staining. SPSS and Graphpad prism software were used for data analysis.

Results: In this study, we found that Cyclin D3 and CDK6 were significantly upregulated in gastric cancer and correlated with poorer overall survival. Further study proved that this complex significantly promoted cell proliferation and cell cycle progression in vitro and accelerated xenografted tumor growth in vivo. Furthermore, we explored the molecular mechanisms through which the complex mediated Rb phosphorylation and then promoted c-Myc expression in vitro, we also found c-Myc could suppress miR$15 \mathrm{a} / 16$ expression in gastric cancer cell. Finally, we found that miR-15a/16 can simultaneously regulate Cyclin D3 and CDK6 expression as direct target genes.

Conclusions: Our findings uncover the Cyclin D3-CDK6/c-Myc/miR-15a/16 feedback loop axis as a pivotal role in the regulation of gastric cancer tumorigenesis, and this regulating axis may provide a potential therapeutic target for gastric cancer treatment.

\section{Background}

Gastric cancer is one of the most common malignant tumors with poor prognosis, because most gastric cancer patients are diagnosed in an advanced or metastatic stages that precludes them from surgical resection. Traditional treatment, including chemotherapy and radiation, showed poor curative effects for advanced gastric cancer (1). Risk factors involved in gastric cancer tumorigenesis have been identified like Helicobacter Pylori infection, high-salt and smoked diet, smoking and chronic gastritis(2). However, the underlying molecular mechanism of gastric cancer has not been fully elucidated. Therefore, it is urgent to explore the new potential molecular mechanism of gastric cancer, and to investigate the hidden physiological and pathological functions, which may identify a new potential target for clinical intervention, diagnosis and even treatment of gastric cancer.

Cyclin D-CDK4/6 complexes are composed of D-type cyclins (D1, D2, and D3) and cyclin-dependent kinases (CDK4 and CDK6). These complexes promote the $\mathrm{G} 1$ phase process by phosphorylating the serine/threonine residues of retinoblastoma tumor suppressor $(\mathrm{Rb})$. Phosphorylated RB is isolated from E2F transcription factors, which facilitate the expression of downstream genes, including Cyclin E, Cyclin A, c-Myc and PCNA. And those genes can accelerate cancer cells proliferation and further promote the 
development of tumor(3). Meanwhile, many studies reported that Cyclin D-CDK4/6 complexes are often overexpressed in various cancers(4-6). In recent years, Cyclin D3-CDK6 complex has been identified as a novel therapeutic target for the treatment of cancer. Palbociclib, an inhibitor targeting Cyclin D3-CDK6 complex, can suppress both cell cycle process in human T-cell acute lymphoblastic leukemia (T-ALL) and tumor progression in animal models of T-ALL (7). Another study found that the inhibition of Cyclin D3CDK6 complex by Ribociclib could promote tumor cell apoptosis and induce cell cycle arrest, which was also confirmed by experiments of T-ALL patient cells in vitro and melanoma Xenograft in vivo(8). In summary, Cyclin D3-CDK6 complex is closely related to cell cycle arrest and cell metabolism, and could even affect tumor cell growth. Based on these facts, this complex might work as a potential target for cancer treatment. As for Cyclin D3 or CDK6 expression level's validation, it was indicated that the expression rate was significantly highly in several tumors in accordance with the Human Protein Atlas database, such as thyroid cancer, gastric cancer, Melanoma and Lymphoma. And on the contrary, it was markedly lower in liver cancer, renal cancer and endometrial cancer.

MicroRNAs (miRNAs) are a class of small (19-23 nucleotides) non-coding RNAs that act as posttranscriptional regulators by binding target mRNAs at complementary sites in their 3'-untranslated regions (3'-UTRs) to repress translation or degrade the mRNA transcripts $(9,10)$. Previous studies have shown that miRNAs are involved in a wide range of cellular pathways, including cell proliferation, differentiation, migration, apoptosis, development and metabolism $(9,11,12)$, and accumulating evidences have demonstrated that dysregulation of miRNAs are often associated with tumourigenesis $(13,14)$. miR-15a and miR-16 are transcribed from miR-15a/16 cluster which is located on the 13q14 human chromosomal region, and function as tumor suppressor in the regulation of tumor cell proliferation, apoptosis, differentiation, and angiogenesis(15). Many studies have shown that miR-15a and miR-16 were downregulated in different types of cancer, such as chronic lymphocytic leukemia (CLL), multiple myeloma and breast cancer(16-18). It has also been reported that c-Myc repressed miR-15a/miR16 expression in mantle cell(19), which suggested that c-Myc might regulate the expression levels of miR$15 a$ and miR-16.

In this study, we investigated the expression levels of Cyclin D3-CDK6 complex in gastric cancer and found this complex was consistently upregulated in gastric cancer tissues and correlated with poorer overall survival. Subsequently, we demonstrated that Cyclin D3-CDK6 complex promoted cell cycle progression and cell proliferation in vitro and accelerated xenografted tumor growth in vivo. Furthermore, we found Cyclin D3-CDK6 complex can suppress the expression of miR-15a/16 by upregulating c-Myc level, meanwhile, we also spotted that miR-15a/16 could target Cyclin D3-CDK6 complex simultaneously. Thus, these results demonstrated that the Cyclin D3-CDK6/c-Myc/miR-15a/16 feedback loop axis contribute to tumorigenesis and may provide a potential therapeutic target for gastric cancer treatment.

\section{Materials And Methods}

Human tissues 
A total of 92 pairs of gastric cancer and matched adjacent noncancerous tissue samples used in this study were collected from 2006 to 2015 at Zhejiang provincial people's hospital, the Affiliated Hospital of Hangzhou medical college. Written informed consents were obtained from all patients. The collection and use of tissues were performed in accordance with The Code of Ethics of the World Medical Association (Declaration of Helsinki) and approved by the Medical Ethics Committee from Hangzhou medical college and Zhejiang provincial people's hospital. The clinical data of these tissues are listed in Table 1.

\section{Immunohistochemistry}

The gastric cancer and matched adjacent noncancerous tissues were fixed in $4 \%$ paraformaldehyde at $4^{\circ} \mathrm{C}$ overnight, dehydrated and embedded in paraffin. Next, the paraffin-embedded tissue samples were cut into serial $3 \mu \mathrm{m}$ section, dewaxed and hydrated, and then $3 \%$ hydrogen peroxide was utilized to block endogenous peroxidase. Subsequently, immunohistochemical staining was carried out using primary antibody Cyclin D3 (1:150) and CDK6 (1:100) overnight at $4^{\circ} \mathrm{C}$. After incubation with the biotinylated secondary antibody for $30 \mathrm{~min}$ at room temperature, the sections were developed by diaminobenzidine (DAB), which were followed by counterstaining with hematoxylin solution and sealing. All information of antibodies used are provided in Supplementary Table 1. A positive result was regarded as the presence of yellow-brown particles in the nucleus and cytoplasm. The staining was divided by color intensity into not colored, light yellow, brown yellow and brown, and graded with 0, 1, 2 and 3 points, respectively. According to the percentage of positive cells in visual field cells, the score was 0 point in $0-5 \%, 1$ point in $6-25 \%, 2$ points in $26-50 \%, 3$ points in $51-75 \%$ and 4 points in $>76 \%$. To calculate the final score, the two items were multiplied. Two observers who are blinded read the results separately.

\section{Cell culture}

The human gastric cancer cell lines (MKN-45, SGC-7901, AGS and MGC-803) and the human gastric epithelial cell line (GES-1) were provided from the Shanghai Institute of Cell Biology, Chinese Academy of Sciences (Shanghai, China). All cell lines were cultured in RPMI 1640 medium supplemented with 10\% fetal bovine serum (FBS, Gibco, Carlsbad, CA, USA) and 1\% penicillin and streptomycin (Invitrogen, San Diego,CA) in a humidified incubator at $37^{\circ} \mathrm{C}$ with $5 \% \mathrm{CO} 2$.

\section{RNA extraction and quantitative RT-PCR}

Total RNA was extracted from cell lines or human tissues using TRIzol Reagent (TaKaRa, Dalian, China) according to the manufacturer's instructions. The concentration and quality of RNA were determined using NANODROP 2000 (Thermo Scientific, Rockford, IL, USA). TaqMan miRNA probes (Applied Biosystems, Foster City, CA) were used to quantify mature miRNAs expression level according to the manufacturer's instructions. The relative amount of miRNA expression was normalized to U6 snRNA expression in this study by the equation $2^{-\triangle \Delta C T}$, where $\triangle \triangle C T=\left(C T_{\text {miRNA }}-C T_{U 6}\right)$ target$\left(\mathrm{CT}_{\text {miRNA }}-\mathrm{CT}_{\mathrm{U}}\right.$ ) control. SYBR Green method was used to quantify mRNAs (Cyclin D3, CDK6, CDK4, Rb, cMyc, Cyclin A2, Cyclin E1, Cyclin E2 and GAPDH) expression level according to the manufacturer's instructions. The relative amount of each mRNA was normalized to GAPDH by the equation $2^{-\triangle \Delta C T}$, where 
$\triangle \triangle C T=\left(C T m R N A-C T_{G A P D H}\right)$ target- $\left(C T m R N A-C_{G A P D H}\right)$ control. All sequences of the primers used are provided in Supplementary Table 2.

\section{Protein isolation and western blot}

Cells were lysed in RIPA lysis buffer (Beyotime, Shanghai, China) with freshly added proteinase inhibitors PMSF (Beyotime, Shanghai, China) and PI (Thermo Scientific, Rockford, IL, USA) for 30 min on ice. Tissue samples were frozen solid with liquid nitrogen, ground into a powder and then lysed in RIPA lysis buffer supplemented with PMSF and PI on ice for $30 \mathrm{~min}$. After centrifugation at $12,500 \mathrm{r} / \mathrm{m}, 4^{\circ} \mathrm{C}$ for $10 \mathrm{~min}$, the supernatants were collected and the concentration of proteins were quantified using a BCA protein assay kit (Thermo Scientific, Rockford, IL, USA). Equal amounts of protein were separated by SDS-PAGE gel and transferred to PVDF membrane (Millipore Corporation, Billerica, MA, USA). After blocking in 5\% skim milk, the PVDF membranes were incubated with primary antibodies overnight at $4^{\circ} \mathrm{C}$. After washing and incubating with secondary antibodies, the bands were detected with the SuperSignal West Pico chemiluminescence substrate (BIO-RAD, USA). All information of antibodies used are provided in Supplementary Table 1.

\section{Plasmid construction and siRNA interference assay}

A mammalian expression plasmid pcDNA3. $1^{+}$and pCMV-3xflag were purchased from Genescript (Nanjing, China). The full-length open reading frame (ORF) of Cyclin D3 was amplified from cDNA that reverse transcription of MGC-803 cells mRNA, the ORFs of CDK6 and c-Myc were amplified from cDNA that reverse transcription of SGC-7901 cells mRNA, and subcloned into pcDNA3.1 $1^{+}$or pCMV-3xflag plasmid digested with Hind III and EcoRI, respectively, generating pcDNA3. $1^{+}-$CyclinD3, pcDNA3. $1^{+}-\mathrm{CDK} 6$, pcDNA3.1 ${ }^{+}-\mathrm{c}-\mathrm{Myc}$, pCMV-3xflag-Cyclin D3 and pCMV-3xflag-CDK6 plasmid. To construct pLKO.1-TRCshRNA plasmid, we used annealing oligos of Cyclin D3 or CDK6 subcloned into pLK0.1-TRC vector digested with Age I and ECORI, generating pLKO.1-TRC-Cyclin D3-shRNA and pLK0.1-TRC-CDK6-shRNA. All sequences of the clone primers used are provided in Supplementary Table 2. Two siRNAs (siRNA-I and siRNA-II) targeting Cyclin D3, CDK6 and c-Myc were designed and synthesized by Ribobio (Guangzhou, China). A scrambled siRNA served as a negative control (siRNA-NC). The siRNA sequences are provided in Supplementary Table 3.

\section{Construction of Stably Transfected Cell Lines}

The recombinant plasmids were verified by sequencing and co-transfected with pMD2G, pSPAX2 into 293T cells to produce recombinant lenti-virus. SGC-7901 cells were infected with lenti-shRNA-NC (control) or lenti-shRNA-Cyclin D3 and lenti-shRNA-CDK6. Forty-eight hours later, the virus-infected cells were cultured in the growth medium with $2.5 \mu \mathrm{g} / \mathrm{mL}$ puromycin for selection. The knockdown efficiency of Cyclin D3 and CDK6 in surviving cells were confirmed by Western blot.

\section{Xenograft assays in nude mice}


Four-week-old athymic BALB/c nude (nu/nu) mice were purchased from Shanghai SLAC Laboratory Animal Company (Shanghai, China). All mice were housed in SPF animal facility. The animal studies were approved by the Animal Care and Use Committee at Hangzhou Medical College. The methods were performed in accordance with the approved guidelines by Hangzhou Medical College. They were equally divided into 3 groups (6 mice/group) and injected subcutaneously with untreated $2 \times 10^{6}$ SGC-7901 cells (Mock) or SGC-7901 cells infected with the control lentiviral vector (lenti-shRNA-NC) or Cyclin D3/CDK6 knockdown lentiviral vector (lenti-shRNA-Cyclin D3/CDK6). After subcutaneous implantation of cells, animals were observed daily for tumor growth, and measured the tumor volume weekly from 14 days post-implantation. Tumors were harvested at 28 days post-implantation, photographed and the volumes and weights of the tumors were recorded. Parts of tumors were used for protein and RNA extraction, and remainder were fixed in $4 \%$ paraformaldehyde and were subjected to immunohistochemical analysis using Cyclin D3, CDK6, PCNA and Ki-67 staining. All information of antibodies used are provided in Supplementary Table 1.

\section{miRNA target prediction}

The miR-15a/16 can simultaneously target Cyclin D3 and CDK6, which were determined using algorithms from TargetScan (http://genes.mit.edu/targetscan/), and RNAhybrid (https://bibiserv.cebitec.unibielefeld.de/rnahybrid/).

\section{Luciferase assay}

To construct a luciferase reporter carrying the mRNA 3'UTR of Cyclin D3 or CDK6 with a putative miR-15a and miR-16 binding sites, we amplified a 674 bp Cyclin D3 3'UTR region including each two binding sites of miR-15a and miR-16 from MGC-803 cDNA, and amplified a 1471 bp CDK6 3'UTR region including each two binding sites from SGC-7901 cDNA. All sequences of the clone primers used are provided in Supplementary Table 2. The PCR amplified product was cloned into the pMIR-Report plasmid (Ambion, Austin, TX, USA) at the Spe I \& Mlu I site. The pMIR-Report plasmid that carried the mutant Cyclin D3 or CDK6 3'UTR region was using the Site-Directed Gene Mutagenesis Kit and specific primers containing mutated nucleotides, the sequences of these primers used are provided in Supplementary Table 2. These insertions were verified by DNA sequencing. For the luciferase reporter assays, $293 \mathrm{~T}$ cells were cultured in 24-well plates, and each well was transfected with $0.2 \mu \mathrm{g}$ firefly luciferase reporter plasmid, $0.15 \mu \mathrm{g} \beta$ galactosidase expression plasmid (Ambion, Austin, TX, USA), and equal amounts ( $25 \mathrm{pmol}$ ) of miR-15a or miR-16 or mixture using Lipofectamine 3000 (Invitrogen). The $\beta$-galactosidase plasmid was used as transfection control. After 24 hours transfection, the luciferase activity was analyzed using luciferase assay kits (Promega, Madison, WI, USA).

\section{Cell cycle assay}

To assess the cell cycle, collected cells were washed with PBS buffer in twice, and fixed in $75 \%$ ethanol overnight. Then, the fixed cells were washed with PBS buffer and incubated with $50 \mu \mathrm{g} / \mathrm{ml}$ RNase A for 30 min at $37^{\circ} \mathrm{C}$, followed by staining for DNA content was performed using $50 \mathrm{mg} / \mathrm{ml}$ propidium iodide (BD 
Biosciences, San Jose, CA). Analysis was performed on a fluorescence-activated cell-sorting (FACS) flow cytometer (BD Biosciences, San Jose, CA) with Cell Quest Pro software.

\section{Cell proliferation assay}

Cells were seed into 96-well plates and incubated in RPMI 1640 medium supplemented with 5\% FBS. The cell proliferation rate was measured using the Cell Counting Kit-8 (CK04-500, Dojindo, Japan) after 12, 24, $36,48,60 \mathrm{~h}$ transfection according to the manufacturer's instruction. Absorbance was measured at a wavelength of $450 \mathrm{~nm}$.

\section{EdU proliferation assay}

To assess cell proliferation, SGC-7901 cells and MGC-803 cells were seeded into 6-well plates, after 24 hours transfection, equal amounts were seeded in triplicate into 96-well plates allowed to attach overnight. The cell proliferation was measured using EdU Cell Proliferation Assay Kit (Ribobio, Guangzhou, China) according to the manufacturer's instructions. Cells were incubated in $50 \mu \mathrm{M}$ Edu for 5 hours and fixed in $4 \%$ paraformaldehyde for $30 \mathrm{~min}$ at room temperature. Next, these cells were permeabilization in PBS with $0.5 \%$ Triton X-100 for 10 min. Subsequently, the cells were incubated in Apollo staining solution for $30 \mathrm{~min}$ and then incubated in Hoechst 33342 for $30 \mathrm{~min}$. The proportion of nucleated cells incorporating EdU was determined by fluorescence microscopy.

\section{Statistical analysis}

All data was analyzed using Student's t-test in SPSS statistical software and presented as the mean value $\pm S D$, with $p$ value $<0.05$ was considered statistically significant. $p<0.05$ (indicated by *),$<0.01$ (indicated by $* *$ ) or $<0.001$ (indicated by $* \star *$ ).

\section{Results}

\section{Cyclin D3-CDK6 complex was upregulated in gastric cancer tissues and gastric cancer cell line}

Cyclin D3-CDK6 complex represents a powerful factor that associates with cancer cell cycle arrest and cancer cell metabolism, and might work as a potential target for cancer treatment. Human Protein Atlas database was used to analyze expression level of this complex in various tumors, the results indicated that the expression rate was significantly highly in thyroid cancer, gastric cancer, Melanoma and Lymphoma. Oppositely, it was markedly lower in liver cancer, renal cancer and endometrial cancer (Supplementary Figure 1). In this study, we aimed to examine the expression pattern of Cyclin D3-CDK6 complex in human gastric cancer tissues, immunohistochemical staining for Cyclin D3 and CDK6 were performed on tissue microarrays consisting of 92 gastric cancer and adjacent noncancerous gastric tissues, the results showed that the expression levels of Cyclin D3 and CDK6 were significantly increased in gastric cancer tissues compared to adjacent noncancerous tissues (Figure 1A-C). And Cyclin D3 expression was positively correlation with CDK6 expression in gastric cancer tissues (Figure 1D). We next explored whether the expression level of Cyclin D3 or CDK6 was associated with the survival of these 
gastric cancer patients. The statistical analysis was performed by using the standard statistical methods for follow-up analysis of 92 participants: Kaplan-Meier survival analyses showed that patients with high expression level of Cyclin D3 or CDK6 were correlated with poorer overall survival (Figure 1E and F). Then, we investigated the expression levels of Cyclin D3-CDK6 complex in 15 pairs of human gastric cancer tissues. The results showed that the protein levels of Cyclin D3 and CDK6 were upregulated in gastric cancer tissues (Figure 1G). Subsequently, we measured the expression levels of Rb, Cyclin D3, CDK6 and CDK4 in gastric epithelial cell line GES- 1 and a panel of 4 human gastric cancer cell lines (MKN-45, SGC7901, AGS, MGC-803). The protein expression levels of Rb were significantly downregulated in human gastric cancer cell lines. Interestingly, the mRNA levels of Rb were observed to increase in MKN45 and SGC-7901, while no significant differences were found in AGS, MGC-803 and GES-1. The protein and mRNA level of Cyclin D3 and CDK6 were upregulated in gastric cancer cell lines, meanwhile, there were no significant differentiation in the protein and mRNA level of CDK4 between gastric cancer cell lines and GES-1 cell line (Figure 1H, Supplementary Figure 2). Taken together, these results revealed that Cyclin D3CDK6 complex was upregulated in gastric cancer tissues and gastric cancer cell line.

\section{Cyclin D3-CDK6 complex promoted gastric cancer cell proliferation and accelerated cell cycle progression}

To investigate the function of Cyclin D3-CDK6 complex in gastric cancer tumorigenesis, we assessed the role of this complex on cell cycle and cell proliferation status after the overexpression or knockdown of Cyclin D3 and CDK6 separately or simultaneously. Considering the low expression levels of this complex in SGC-7901 cell line (Figure 1H), we enhanced this complex expression in SGC-7901 and GES-1 cell line by transfecting with overexpression plasmid. Two siRNA targeting different sites of Cyclin D3 or CDK6 were designed to knock down this complex, respectively. Preliminary experimental results were showed in Supplementary Figure 3A-D. Then, because Cyclin D3-CDK6 complex is highly expressed in MGC-803 cell line (Figure $1 \mathrm{H})$, and we chose the siRNA with better inhibitory effect to suppress its expression in the MGC-803 and GES-1cell lines. The efficiency of overexpression and knockdown of this complex were shown in Figure 2A and 2B. And the mRNA levels were shown in Supplementary Figure 4. Cell cycle assay, EdU proliferation assay and CCK8 assay indicated that overexpression of this complex promoted cell cycle progression and cell proliferation (Figure 2C, E, G and I, Supplementary Figure 5A-C), whereas the knockdown through siRNA suppressed cell cycle progression and decreased cell proliferation (Figure 2D, F, H and J, Supplementary Figure 5D-F). Moreover, we also noticed a more significant effect in a combined overexpression or inhibition of this complex. These results demonstrated that Cyclin D3-CDK6 complex played as an oncogene role in gastric cancer.

\section{Cyclin D3-CDK6 complexpromoted growth of gastric cancer cells in vivo}

To further confirm the effects of Cyclin D3-CDK6 complex on the formation and growth of gastric tumor in vivo, we established gastric cancer xenograft mouse model. Firstly, SGC-7901 cells were infected with lenti-shRNA-NC (control) or lenti-shRNA-Cyclin D3 and lenti-shRNA-CDK6. SGC-7901(Mock) and infected cells were implanted subcutaneously into 4-week-old nude mice (Figure 3A). After 14 days implantation, tumor volumes were measured weekly (Figure 3B). We sacrificed the mice at 28 days post-implantation. 
And a remarkable reduction in volume and weight of the tumors was observed in the Cyclin D3/CDK6 knockdown group compared to control group and Mock group (Figure $3 \mathrm{C}$ and D). Subsequently, total protein was extracted from each tumor and used to evaluate the expression levels of Cyclin D3 and CDK6. As expected, the tumors from knockdown group showed a significant decrease in Cyclin D3 and CDK6 expression compared to tumors from the control group and Mock group (Figure 3E). Finally, the proliferative activity of the tumor cells was assessed via immunohistochemical staining for PCNA and Ki67, meanwhile, staining for Cyclin D3 and CDK6. As measured by the staining intensity of antibody, we found that the levels of Cyclin D3, CDK6, PCNA and Ki-67 were significantly decreased in knockdown group (Figure 3F). These results revealed that the downregulation of Cyclin D3-CDK6 complex could attenuate gastric tumor growth in vivo.

\section{Cyclin D3-CDK6 complex mediated Rb phosphorylation}

To ascertain how many Rb sites are phosphorylated by Cyclin D3-CDK6 complex, phospho-specific Rb antibodies are used to recognize phosphorylated Rb isoforms, including Serine807/811, Serine780 and Serine795(S807/811, S780 and S795). We ectopically expressed Cyclin D3 and CDK6 in the SGC-7901 cell line by transfecting cells with overexpression plasmid, and then examined Rb phosphorylation level. The result showed the overexpression of Cyclin D3-CDK6 complex enhanced two sites (S807/811 and S795) phosphorylation level, and didn't mediate the Rb S780 site phosphorylation (Figure 4A). The Rb phosphorylation level didn't show any difference when we only reduced the expression level of Cyclin D3 or CDK6 in MGC-803 cell line, respectively. However, when we reduced the expression levels of Cyclin D3 and CDK6 simultaneously, the phosphorylation levels of Rb sites (S807/811 and S795) were significantly inhibited, but it didn't mediate Rb S780 site phosphorylation (Figure 4B). To further investigate these results, Co-IP experiment was performed to confirm the interaction among Cyclin D1, Cyclin D3, CDK4 and CDK6. In addition to CDK6, we found that Cyclin D3 can also bind with CDK4 to form Cyclin D3-CDK4 complex. Besides, Cyclin D1 can interact with CDK6 (Figure 4C, Supplementary Figure 6A and B). Therefore, we speculated that the knockdown of any single gene of Cyclin D3-CDK6 complex cannot mediate the phosphorylation of Rb successfully, unless downregulate this complex simultaneously. These results revealed that Cyclin D3-CDK6 complex mediated two Rb sites (S807/811 and S795) phosphorylation in gastric cancer cell line (Figure 4D).

\section{Cyclin D3-CDK6 complex promoted c-Myc, Cyclin A2 and Cyclin E2 expression}

Cyclin D-CDK4/6 complex shuttled into nucleus and phosphorylated multiple sites of Rb, then released repressor E2Fs from Rb inhibition to initiate gene expression, including c-Myc, Cyclin A and Cyclin E. To further investigate whether Cyclin D3-CDK6 complex enhanced these gene expression, we overexpressed Cyclin D3-CDK6 complex in SGC-7901 cell line, as well as knockdown this complex in MGC-803 cell line.

The results showed the overexpression of this complex increased both mRNA and protein levels of c-Myc, Cyclin A and Cyclin E (Figure 5A and B). On the contrary, the mRNA and protein levels of c-Myc, Cyclin A and Cyclin E2 were significantly downregulated in MGC-803 cell line transfected with Cyclin D3 and CDK6 siRNAs simultaneously (Figure 5C and D). However, Cyclin E1 didn't vary in both mRNA and protein levels 
by either overexpression or inhibition of Cyclin D3-CDK6 complex (Figure 5A-D). Taken together, our results suggested that Cyclin D3-CDK6 complex promoted c-Myc, Cyclin A and Cyclin E2 expression by mediating $\mathrm{Rb}$ phosphorylation in gastric cancer cell line.

\section{Cyclin D3-CDK6 complex suppressed miR-15a/16 expression by inducing c-Myc overexpression}

Firstly, we measured the expression levels of miR-15a and miR-16 in gastric cancer cell lines (MKN-45, SGC-7901, AGS and MGC-803) and the human gastric epithelial cell line (GES-1). The results turned out that miR-15a and miR-16 levels were consistently decreased in gastric cancer cell lines compared with GES-1 (Figure 6A and B). Subsequently, we ectopically expressed c-Myc in the gastric cancer cell lines by transfecting cells with pCDNA-3.1 $1^{+}-\mathrm{c}-\mathrm{Myc}$ or c-Myc siRNA and then examined the expression levels of miR-15a and miR-16. The efficiency of c-Myc overexpression in SGC-7901 cells is shown in Figure 6C and the mRNA level is shown in Supplementary Figure 7A. The overexpression of c-Myc significantly inhibited miR-15a and miR-16 expression (Figure 6E and F). Moreover, we knockdown c-Myc expression in MGC803 cell line, the efficiency of siRNA is shown in Figure 6D and the mRNA level is shown in Supplementary Figure 7B. As expected, knockdown of c-Myc significantly enhanced miR-15a and miR-16 expression (Figure 6G and $\mathrm{H}$ ). Furthermore, to further confirm the fact that Cyclin D3-CDK6 complex could suppress miR-15a/16 expression by promoting c-Myc overexpression. We overexpressed Cyclin D3-CDK6 complex in SGC-7901 cell line, and knockdown this complex in MGC-803 cell line. The results showed miR-15a and miR-16 were significantly downregulated in SGC-7901 cell line and upregulated in MGC-803 cell line (Figure 6I-L). Finally, we found similar results in tumors of xenograft mice. Compared with control group and Mock group, the expression levels of miR-15a and miR-16 were upregulated in Cyclin D3/CDK6 knockdown group (Figure 6M and N). All these results suggested that Cyclin D3-CDK6 complex can suppress miR-15a/16 expression by inducing c-Myc overexpression.

\section{Cyclin D3-CDK6 complex were direct targets of miR-15a/16}

We used a bioinformatics software Targetscan and RNAhybrid to predict potential miRNAs that target Cyclin D3 and CDK6. Interestingly, we found miR-15a and miR-16 can simultaneously target Cyclin D3 and CDK6. As predicted by Targetscan, miR-15a and miR-16 have 2 conserved binding sites in 3'UTR of Cyclin D3 and CDK6, respectively. The minimum free energy values of the miR-15a-Cyclin D3 mRNA hybridisations were -18.7 and $-20.1 \mathrm{kcal} / \mathrm{mol}$, and miR-16-Cyclin D3 mRNA hybridisations were -17.9 and $-20.0 \mathrm{kcal} / \mathrm{mol}$ (Figure 7A). And the minimum free energy values of the miR-15a-CDK6 mRNA hybridisations were -20.7 and $-20.4 \mathrm{kcal} / \mathrm{mol}$, and miR-16-CDK6 mRNA hybridisations were -16.3 and $-19.4 \mathrm{kcal} / \mathrm{mol}$ (Figure 7B). To further confirm whether miR-15a and miR-16 directly target Cyclin D3 and CDK6 by binding to the corresponding 3'-UTRs, we cloned the 3'-UTR from Cyclin D3 and CDK6 into the pMIR-Report luciferase reporter vector and co-transfected these vectors with miR-15a or miR-16 mimics into 293T cell line. As expected, overexpression of miR-15a and miR-16 resulted in reduction of luciferase reporter activity (Figure 7C). Meanwhile, we generated a point mutation into the corresponding complementary sites in the Cyclin D3 and CDK6 3'-UTR to eliminate the predicted miR-15a and miR-16 binding sites (Figure 7A and B). The mutated luciferase reporter was unaffected by overexpression of 
miR-15a or miR-16 (Figure 7D). These results suggested that the binding site strongly contributes to the miRNA:mRNA interaction and mediates the post-transcriptional repression of Cyclin D3 and CDK6 expression. To further validate the luciferase activity results, firstly, we measured the expression patterns of miR-15a and miR-16 in 15 pairs of human gastric cancer tissues. As shown in Figure 7E, the miR-15a and miR-16 levels were downregulated in gastric cancer tissues compared to adjacent noncancerous tissues. Subsequently, we ectopically expressed miR-15a and miR-16 in the GES-1 and SGC-7901 cell lines by transfecting cells with miR-15a and miR-16 mimics, the efficiency of the overexpression in cells was shown in Supplementary Figure 8A and B. The protein and mRNA levels of Cyclin D3 and CDK6 were significantly downregulated by miR-15a and miR-16 overexpression in cells (Supplementary Figure 8C-F). Finally, we infected SGC-7901 cells with a miR-15a and miR-16 overexpression lentivirus, the efficiency of overexpression of miR-15a and miR-16 in cells was shown in Figure 7F and the protein and mRNA levels of Cyclin D3 or CDK6 were significantly decreased (Supplementary Figure 9 and Figure 7G). Meanwhile, cell cycle assay, EdU proliferation assay and CCK8 assay indicated that overexpression of miR-15a/16 could suppress cell cycle progression and cell proliferation (Figure $7 \mathrm{H}-\mathrm{K}$ ). Taken together, these results showed that miR-15a and miR-16 function as tumor suppressive miRNAs to inhibit gastric cancer cell cycle progression and suppress cancer cell proliferation by simultaneously targeting Cyclin D3 and CDK6.

\section{Discussion}

Cell cycle phase transition is controlled by cell-cycle checkpoints and a particularly critical checkpoint is the entrance from $\mathrm{G} 1$ phase to S phase(3). Cyclin D-CDK4/6 complex controls cell cycle transition from G1 phase to $S$ phase, and plays as an important role in cell proliferation. Extensive studies have shown that Cyclin D1 functions as an oncogene, which is upregulated in breast cancer, gastric cancer, esophageal cancer, lung cancer and melanoma(20-25). Cyclin D2 is aberrantly expressed in colorectal cancer, B-cell chronic lymphocytic leukemia (B-CLL) and other tumors $(26,27)$. Recent reports have indicated that Cyclin D3 is a crucial factor of leukemia pathogenesis, and suggested that Cyclin D3 is a potential therapeutic target in devastating blood tumor(7, 8, 28, 29). Cyclin-dependent kinases (CDKs), a well-characterized family of serine and threonine kinases, plays an important role in cell cycle regulation by phosphorylation of $\mathrm{Rb}$ and other substrates(30). $\mathrm{Rb}$ is a key regulator of entry into cell division that acts as a tumor suppressor, plays as a transcription repressor of E2F1 target genes. When Rb is in underphosphorylated form, it would interact with E2F1 and represses its transcription activity, leading to cell cycle arrest, and this effect can be reversed by the hyperphosphorylation of Rb induced by CDK6 and CDK4, which leading to cell cycle progression(31). CDK4 and CDK6 are important members of the CDK family, which are responsible for cycle progression through the $\mathrm{G} 1$ phase(32). In this study, we validated that Cyclin D3-CDK6 complex was upregulated in many gastric cancer tissues and could promote gastric cancer cell proliferation in vitro and facilitate tumor growth in vivo, and high expression level of Cyclin D3 or CDK6 was associated with poor overall survival in gastric cancer patients. Given the previous research and our results, it is reasonable to consider that Cyclin D3-CDK6 complex might be a new therapeutic target for gastric cancer. 
The Cyclin D-CDK4/6-Rb signaling pathway plays a pivotal role in regulating cancer cell proliferation by modulating the transition of G1/S phase. Our results revealed that Cyclin D3-CDK6 complex can increase $\mathrm{Rb}$ protein phosphorylation at Ser807/811 and Ser795 sites, which in turn increases downstream genes expression such as Cyclin A2, Cyclin E2 and c-Myc. Dysregulation of Cyclin A2 has been reported in a variety of cancers, and aberrant expression of Cyclin A2 is closely related to chromosomal instability and cancer cell proliferation(33). Cyclin E/CDK2 complex can promote cell proliferation by triggering the initiation of DNA replication and centrosome duplication $(34,35)$. Cyclin E2 is a member of Cyclin E family, which contributes to the G1/S phase transition, cell proliferation, and cancer progression(36). As an oncogenic transcription factor, c-Myc promotes tumorigenesis by activating or repressing its target genes that control the cell proliferation $(19,37)$. The c-terminal region of c-Myc contains a helix-loop-helix motifs $(\mathrm{b}-\mathrm{HLH})$ and leucine zipper dimerization motif, and its activity is dependent on the formation of heterodimers with MAX, upon which the heterodimers bind to regions of DNA with the CACGTG sequence motif (E-boxes) $(38,39)$. Previous research has indicated that c-Myc can repress miR-15a/16 expression by binding E-Box element in colorectal cancer(40). miR-15a/16 was the first reported miRNA cluster which functions as a tumor suppressor in chronic lymphocytic leukemia (41). Multiple targets have been revealed for miR-15a/16 to exert its tumor-suppressive role, such as Cyclin D1, Cyclin D2, Cyclin E1, CDK4, BCL-2, Chemokine ligand 10(CXCL10) and Wilms' tumor gene(WT1)(15). Our study revealed that c-Myc can also repress miR-15a/16 expression in gastric cancer cells, and miR-15a and miR-16 can simultaneously target Cyclin D3-CDK6 complex. We also noticed that miR-15a and miR-16 were downregulated in gastric cancer, and can suppress cell proliferation and induce G1/S cell cycle arrest. These results indicated that we have identified a novel Cyclin D3-CDK6-pRb-c-Myc-miR-15a/16 circuit pathway to regulate gastric cancer cell proliferation.

At present, Cyclin D-CDK4/6 complex has been considered as a strategic target for antitumor therapy and there are at least three different specific inhibitors of CDK4/ 6 being used in different clinical trials, including Palbociclib (Ibrance, formerly termed PD-0332991, Pfizer), Abemaciclib (LY2835219, Eli Lilly \& Company), and Ribociclib (LEE011, Novartis) $(3,5,32,42)$. And these inhibitors have received regulatory approval in combination with hormonal therapy for treatment of patients with metastatic hormone receptor $(\mathrm{HR})$-positive, Her2-negative breast cancer $(43,44)$. Meanwhile, many evidences have proved its function in the treatment of other cancers. It has also been reported that Palbociclib potentially inhibits both cell cycle entry in human T-ALL as well as disease progression in animal models of T-ALL(7), and Ribociclib could significantly reduce tumor growth in nude mice that grafted with patient-derived melanomas(8). Recent studies demonstrated that Abemaciclib inhibits multiple human cancer xenograft models, including non-small cell lung cancer (NSCLC), melanoma, glioblastoma and mantle cell lymphoma(45-48). In this study, we found Cyclin D3-CDK6 complex significantly promoted cell proliferation and cell cycle progression in vitro and accelerated xenografted tumor growth in vivo by regulating the $\mathrm{Rb} / \mathrm{c}-\mathrm{Myc} / \mathrm{miR}-15 \mathrm{a} / 16$ axis in a feedback loop. These results suggested that, by targeting Cyclin D3-CDK6 complex signal pathway, inhibitors of Cyclin D-CDK4/6 might work as a potential therapeutic agent in the treatment of gastric cancer. A few recent studies have indicated that Palbociclib 
can provide useful therapeutic benefit for gastric cancer $(49,50)$. Therefore, our findings could provide a rationale for inhibitors of $\mathrm{CDK} 4 / 6$ for treatment of gastric cancer.

\section{Conclusion}

Taken together, our findings demonstrated that Cyclin D3-CDK6 complex is highly expressed in gastric cancer tissue. Overexpression of this complex is correlated with poorer overall survival, as well as the gastric cancer cell proliferation and cell cycle progression. Further study showed this complex can accelerate xenografted tumor growth in vivo. Moreover, our study showed that Cyclin D3-CDK6 complex can mediate $\mathrm{Rb}$ phosphorylation and then enhance c-Myc expression in vitro. We also proved that c-Myc can suppress miR-15a/16 expression in gastric cancer cell. Further research indicated that miR-15a/16 can simultaneously regulate Cyclin D3 and CDK6 expression in gastric cancer. To conclude, these findings showed that Cyclin D3-CDK6 complex facilitates gastric cancer tumourigenesis through regulating the c-Myc/miR-15a/16 axis in a feedback loop (Figure 8), and this regulating axis may work as a potential therapeutic target for gastric cancer treatment.

\section{Abbreviations}

CDKs: Cyclin-dependent kinases; Rb: Retinoblastoma tumor suppressor; T-ALL: T-cell acute lymphoblastic leukemia; MicroRNAs: miRNAs; 3'-UTRs: 3'-untranslated regions; CLL: Chronic lymphocytic leukemia; FBS: Fetal bovine serum; S807/811: Serine807/811; S780: Serine780; S795: Serine795; b-HLH: Helix-loop-helix motifs; CXCL10: Chemokine ligand 10; WT1: Wilms' tumor gene; NSCLC: Non-small cell lung cancer

\section{Declarations}

Ethics approval and consent to participate

The human cancer tissues used in this study were approved by the Medical Ethics Committee from Hangzhou medical college and Zhejiang provincial people's hospital. All patients gave written informed consent. The animal studies were performed in accordance with the approved guidelines by Hangzhou Medical College.

Consent for publication

All patients involved in this study agree the publication of the data.

Availability of data and material

The datasets used and/or analyzed during the current study were available from the corresponding authors on reasonable request.

Competing interests 
The authors declare that there are no competing interests associated with the manuscript.

Funding

This work was supported by grants from the National Natural Science Foundation of China (No. 81801513).

Authors' Contributions

These authors were involved in this manuscript: YTH, JXL, LY and CY designed this study and drafted the manuscript. JBZ collected the clinical data. YTH, JBZ, WH, LS, HXC and YQW performed the experiments. YTH and JBZ analyzed and interpreted the data. LY and LJC provided technical or material support. All authors contributed to the reviewing of the manuscript, and approved the final manuscript for submission.

Acknowledgements

We would like to thank for all the members who helped with this study.

\section{References}

1. Siegel RL, Miller KD, Jemal A. Cancer statistics, 2018. CA: a cancer journal for clinicians. 2018;68(1):7-30.

2. Zhou Y, Huang T, Zhang J, Wong CC, Zhang B, Dong Y, et al. TEAD1/4 exerts oncogenic role and is negatively regulated by miR-4269 in gastric tumorigenesis. Oncogene. 2017;36(47):6518-30.

3. VanArsdale T, Boshoff C, Arndt KT, Abraham RT. Molecular Pathways: Targeting the Cyclin D-CDK4/6 Axis for Cancer Treatment. Clinical cancer research : an official journal of the American Association for Cancer Research. 2015;21(13):2905-10.

4. Sherr CJ, Roberts JM. Living with or without cyclins and cyclin-dependent kinases. Genes \& development. 2004;18(22):2699-711.

5. Sherr CJ, Beach D, Shapiro GI. Targeting CDK4 and CDK6: From Discovery to Therapy. Cancer discovery. 2016;6(4):353-67.

6. Deshpande A, Sicinski P, Hinds PW. Cyclins and cdks in development and cancer: a perspective. Oncogene. 2005;24(17):2909-15.

7. Sawai CM, Freund J, Oh P, Ndiaye-Lobry D, Bretz JC, Strikoudis A, et al. Therapeutic targeting of the cyclin D3:CDK4/6 complex in T cell leukemia. Cancer cell. 2012;22(4):452-65.

8. Wang H, Nicolay BN, Chick JM, Gao X, Geng Y, Ren H, et al. The metabolic function of cyclin D3-CDK6 kinase in cancer cell survival. Nature. 2017;546(7658):426-30.

9. He L, Hannon GJ. MicroRNAs: small RNAs with a big role in gene regulation. Nature reviews Genetics. 2004;5(7):522-31. 
10. Krol J, Loedige I, Filipowicz W. The widespread regulation of microRNA biogenesis, function and decay. Nature reviews Genetics. 2010;11(9):597-610.

11. Zhu K, Liu L, Zhang J, Wang Y, Liang H, Fan G, et al. MiR-29b suppresses the proliferation and migration of osteosarcoma cells by targeting CDK6. Protein \& cell. 2016;7(6):434-44.

12. Hong $Y$, Liang $H$, Uzair Ur R, Wang $Y$, Zhang $W$, Zhou $Y$, et al. miR-96 promotes cell proliferation, migration and invasion by targeting PTPN9 in breast cancer. Scientific reports. 2016;6:37421.

13. Esquela-Kerscher A, Slack FJ. Oncomirs - microRNAs with a role in cancer. Nature reviews Cancer. 2006;6(4):259-69.

14. Liu Y, Chen X, Cheng R, Yang F, Yu M, Wang C, et al. The Jun/miR-22/HuR regulatory axis contributes to tumourigenesis in colorectal cancer. BioMed research international. 2018;17(1):11.

15. Liu T, Xu Z, Ou D, Liu J, Zhang J. The miR-15a/16 gene cluster in human cancer: A systematic review. 2019;234(5):5496-506.

16. Braga TV, Evangelista FCG, Gomes LC, Araujo S, Carvalho MDG, Sabino AP. Evaluation of MiR-15a and MiR-16-1 as prognostic biomarkers in chronic lymphocytic leukemia. Biomedicine \& pharmacotherapy $=$ Biomedecine $\&$ pharmacotherapie. 2017;92:864-9.

17. Zhang L, Zhou L, Shi M, Kuang Y, Fang L. Downregulation of miRNA-15a and miRNA-16 promote tumor proliferation in multiple myeloma by increasing CABIN1 expression. Oncology letters. 2018;15(1):1287-96.

18. Luo Q, Li X, Li J, Kong X, Zhang J, Chen L, et al. MiR-15a is underexpressed and inhibits the cell cycle by targeting CCNE1 in breast cancer. International journal of oncology. 2013;43(4):1212-8.

19. Zhang X, Chen X, Lin J, Lwin T, Wright G, Moscinski LC, et al. Myc represses miR-15a/miR-16-1 expression through recruitment of HDAC3 in mantle cell and other non-Hodgkin B-cell lymphomas. Oncogene. 2012;31(24):3002-8.

20. Ormandy CJ, Musgrove EA, Hui R, Daly RJ, Sutherland RL. Cyclin D1, EMS1 and 11q13 amplification in breast cancer. Breast cancer research and treatment. 2003;78(3):323-35.

21. Al-Kuraya K, Schraml P, Torhorst J, Tapia C, Zaharieva B, Novotny H, et al. Prognostic relevance of gene amplifications and coamplifications in breast cancer. Cancer research. 2004;64(23):8534-40.

22. Adelaide J, Monges G, Derderian C, Seitz JF, Birnbaum D. Oesophageal cancer and amplification of the human cyclin D gene CCND1/PRAD1. British journal of cancer. 1995;71(1):64-8.

23. George J, Lim JS, Jang SJ, Cun Y, Ozretic L, Kong G, et al. Comprehensive genomic profiles of small cell lung cancer. Nature. 2015;524(7563):47-53.

24. Curtin JA, Fridlyand J, Kageshita T, Patel HN, Busam KJ, Kutzner H, et al. Distinct sets of genetic alterations in melanoma. The New England journal of medicine. 2005;353(20):2135-47.

25. Deng M, Zeng C, Lu X, He X, Zhang R, Qiu Q, et al. miR-218 suppresses gastric cancer cell cycle progression through the CDK6/Cyclin D1/E2F1 axis in a feedback loop. Cancer letters. 2017;403:17585. 
26. Leach FS, Elledge SJ, Sherr CJ, Willson JK, Markowitz S, Kinzler KW, et al. Amplification of cyclin genes in colorectal carcinomas. Cancer research. 1993;53(9):1986-9.

27. Delmer A, Ajchenbaum-Cymbalista F, Tang R, Ramond S, Faussat AM, Marie JP, et al. Overexpression of cyclin D2 in chronic B-cell malignancies. Blood. 1995;85(10):2870-6.

28. Dolezal E, Infantino S, Drepper F, Borsig T, Singh A, Wossning T, et al. The BTG2-PRMT1 module limits pre-B cell expansion by regulating the CDK4-Cyclin-D3 complex. Nature immunology. 2017;18(8):911-20.

29. Curiel-Olmo S, Mondejar R, Almaraz C, Mollejo M, Cereceda L, Mares R, et al. Splenic diffuse red pulp small B-cell lymphoma displays increased expression of cyclin D3 and recurrent CCND3 mutations. Blood. 2017;129(8):1042-5.

30. Goel S, DeCristo MJ, McAllister SS, Zhao JJ. CDK4/6 Inhibition in Cancer: Beyond Cell Cycle Arrest. Trends in cell biology. 2018;28(11):911-25.

31. Chung M, Liu C, Yang HW, Koberlin MS, Cappell SD, Meyer T. Transient Hysteresis in CDK4/6 Activity Underlies Passage of the Restriction Point in G1. Molecular cell. 2019;76(4):562-73 e4.

32. Musgrove EA, Caldon CE, Barraclough J, Stone A, Sutherland RL. Cyclin D as a therapeutic target in cancer. Nature reviews Cancer. 2011;11(8):558-72.

33. Gopinathan L, Tan SL, Padmakumar VC, Coppola V, Tessarollo L, Kaldis P. Loss of Cdk2 and cyclin A2 impairs cell proliferation and tumorigenesis. Cancer research. 2014;74(14):3870-9.

34. Caldon CE, Sergio CM, Kang J, Muthukaruppan A, Boersma MN, Stone A, et al. Cyclin E2 overexpression is associated with endocrine resistance but not insensitivity to CDK2 inhibition in human breast cancer cells. Molecular cancer therapeutics. 2012;11(7):1488-99.

35. Kanai M, Crowe MS, Zheng Y, Vande Woude GF, Fukasawa K. RhoA and RhoC are both required for the ROCK II-dependent promotion of centrosome duplication. Oncogene. 2010;29(45):6040-50.

36. Wu D, He J, Zhang W, Wang K, Jin S, Li J, et al. CARM1 promotes non-small cell lung cancer progression through upregulating CCNE2 expression. Aging. 2020;12(11):10578-93.

37. Meyer N, Penn LZ. Reflecting on 25 years with MYC. Nature reviews Cancer. 2008;8(12):976-90.

38. God JM, Cameron C, Figueroa J, Amria S, Hossain A, Kempkes B, et al. Elevation of c-MYC disrupts HLA class II-mediated immune recognition of human B cell tumors. Journal of immunology. 2015;194(4):1434-45.

39. Dang CV. MYC on the path to cancer. Cell. 2012;149(1):22-35.

40. Xue G, Yan HL, Zhang Y, Hao LQ, Zhu XT, Mei Q, et al. c-Myc-mediated repression of miR-15-16 in hypoxia is induced by increased HIF-2alpha and promotes tumor angiogenesis and metastasis by upregulating FGF2. Oncogene. 2015;34(11):1393-406.

41. Cho WC. OncomiRs: the discovery and progress of microRNAs in cancers. Molecular cancer. 2007;6:60.

42. O'Leary B, Finn RS, Turner NC. Treating cancer with selective CDK4/6 inhibitors. Nature reviews Clinical oncology. 2016;13(7):417-30. 
43. Jin D, Tran N, Thomas N, Tran DD. Combining CDK4/6 inhibitors ribociclib and palbociclib with cytotoxic agents does not enhance cytotoxicity. PloS one. 2019;14(10):e0223555.

44. Kwapisz D. Cyclin-dependent kinase 4/6 inhibitors in breast cancer: palbociclib, ribociclib, and abemaciclib. Breast cancer research and treatment. 2017;166(1):41-54.

45. Gelbert LM, Cai S, Lin X, Sanchez-Martinez C, Del Prado M, Lallena MJ, et al. Preclinical characterization of the CDK4/6 inhibitor LY2835219: in-vivo cell cycle-dependent/independent antitumor activities alone/in combination with gemcitabine. Investigational new drugs. 2014;32(5):82537.

46. Tate SC, Cai S, Ajamie RT, Burke T, Beckmann RP, Chan EM, et al. Semi-mechanistic pharmacokinetic/pharmacodynamic modeling of the antitumor activity of LY2835219, a new cyclindependent kinase 4/6 inhibitor, in mice bearing human tumor xenografts. Clinical cancer research : an official journal of the American Association for Cancer Research. 2014;20(14):3763-74.

47. Yadav V, Burke TF, Huber L, Van Horn RD, Zhang Y, Buchanan SG, et al. The CDK4/6 inhibitor LY2835219 overcomes vemurafenib resistance resulting from MAPK reactivation and cyclin D1 upregulation. Molecular cancer therapeutics. 2014;13(10):2253-63.

48. Patnaik A, Rosen LS, Tolaney SM, Tolcher AW, Goldman JW, Gandhi L, et al. Efficacy and Safety of Abemaciclib, an Inhibitor of CDK4 and CDK6, for Patients with Breast Cancer, Non-Small Cell Lung Cancer, and Other Solid Tumors. Cancer discovery. 2016;6(7):740-53.

49. Wang D, Sun Y, Li W, Ye F, Zhang Y, Guo Y, et al. Antiproliferative effects of the CDK6 inhibitor PD0332991 and its effect on signaling networks in gastric cancer cells. International journal of molecular medicine. 2018;41(5):2473-84.

50. Min A, Kim JE, Kim YJ, Lim JM, Kim S, Kim JW, et al. Cyclin E overexpression confers resistance to the CDK4/6 specific inhibitor palbociclib in gastric cancer cells. Cancer letters. 2018;430:123-32.

\section{Tables}

Table1. Analysis of the correlation between the expression of Cyclin D3 and CDK6 in gastric cancer and its clinicopathological characteristics 


\begin{tabular}{|c|c|c|c|c|c|c|c|}
\hline & \multirow[t]{2}{*}{ Cases } & \multicolumn{3}{|c|}{ Cyclin D3 } & \multicolumn{3}{|c|}{ CDK6 } \\
\hline & & Low & High & $\mathrm{p}$ value & Low & High & $\mathrm{p}$ value \\
\hline Sex & & & & 0.072 & & & 0.780 \\
\hline Female & 33 & 21 & 12 & & 22 & 11 & \\
\hline Male & 59 & 26 & 33 & & 41 & 18 & \\
\hline Age(year) & & & & 0.820 & & & 0.056 \\
\hline 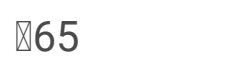 & 42 & 22 & 20 & & 33 & 9 & \\
\hline$\geq 65$ & 50 & 25 & 25 & & 30 & 20 & \\
\hline Grade & & & & 0.216 & & & 0.020 \\
\hline 2 & 35 & 15 & 20 & & 29 & 6 & \\
\hline 3 & 57 & 32 & 25 & & 34 & 23 & \\
\hline T stage & & & & 0.708 & & & 0.097 \\
\hline T1/T2 & 15 & 7 & 8 & & 13 & 2 & \\
\hline T3/T4 & 77 & 40 & 37 & & 50 & 27 & \\
\hline $\mathrm{N}$ stage & & & & 0.364 & & & 0.491 \\
\hline NO & 23 & 10 & 13 & & 17 & 6 & \\
\hline N1/N2/N3 & 68 & 37 & 31 & & 45 & 23 & \\
\hline M stage & & & & 0.040 & & & 0.846 \\
\hline MO & 84 & 46 & 38 & & 57 & 27 & \\
\hline M1 & 7 & 1 & 6 & & 5 & 2 & \\
\hline TNM stage & & & & 0.931 & & & 0.097 \\
\hline I/ II & 36 & 19 & 17 & & 28 & 8 & \\
\hline III/ IV & 54 & 28 & 26 & & 33 & 21 & \\
\hline
\end{tabular}

Figures 
A

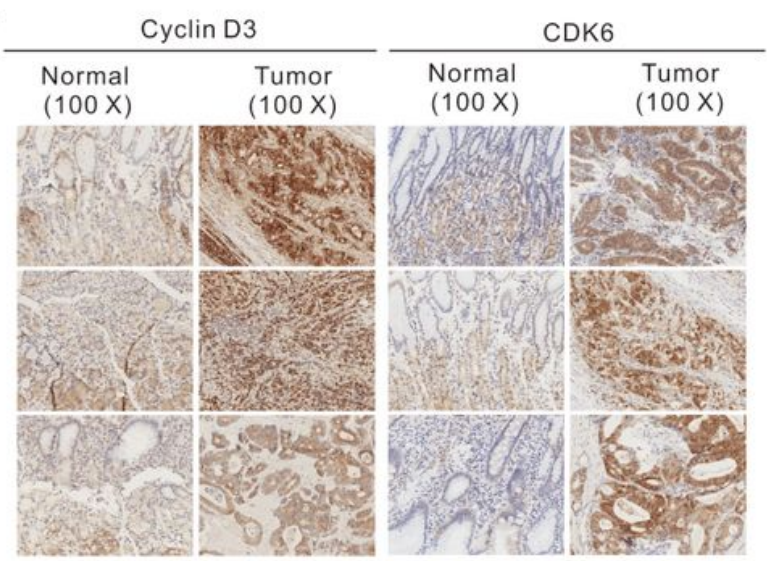

B

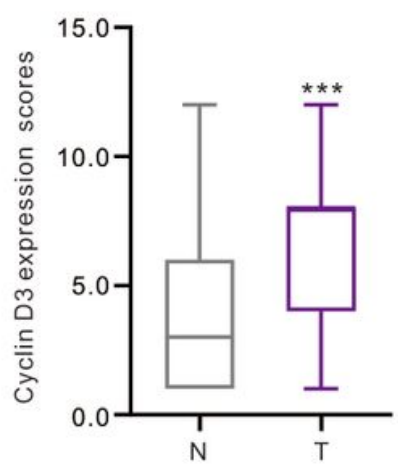

C
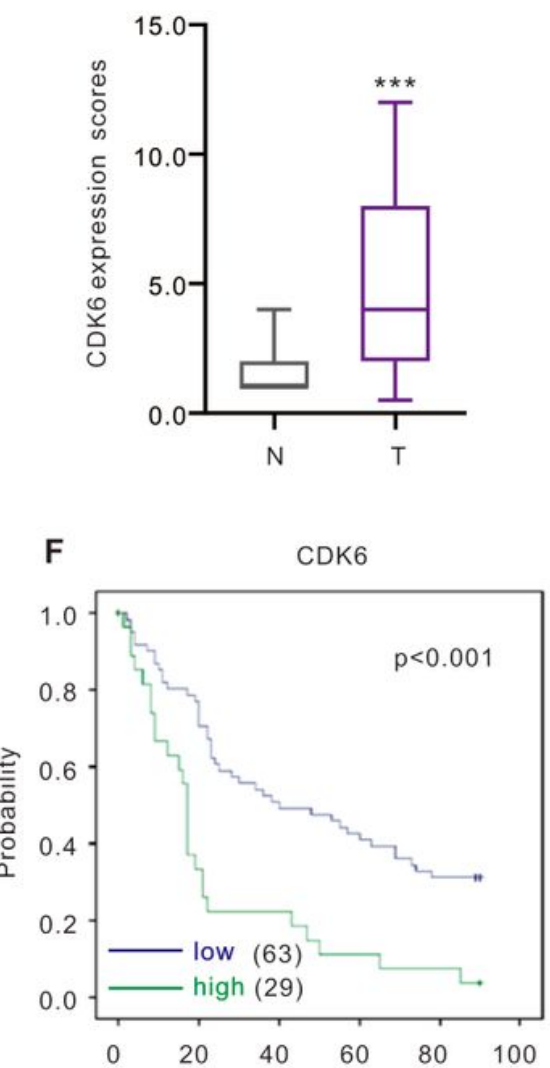

D

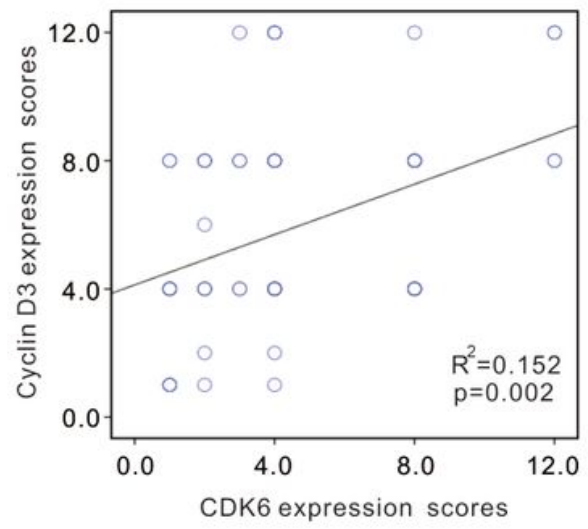

G
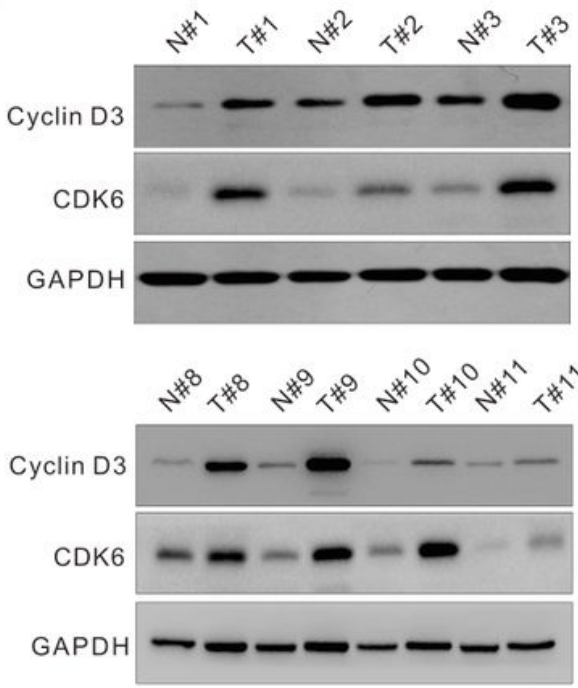

Cyclin D3

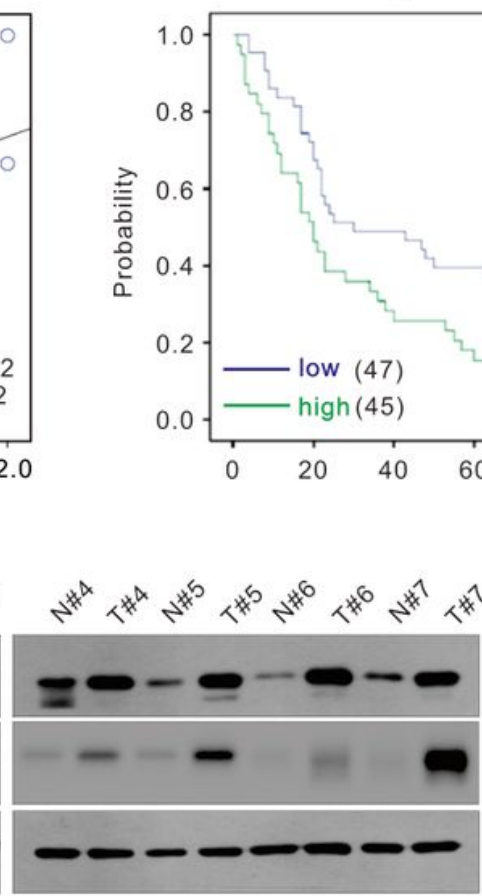

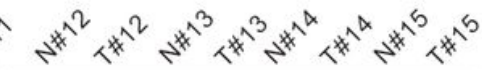

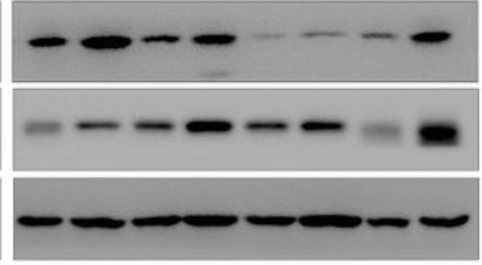

$\mathrm{H}$

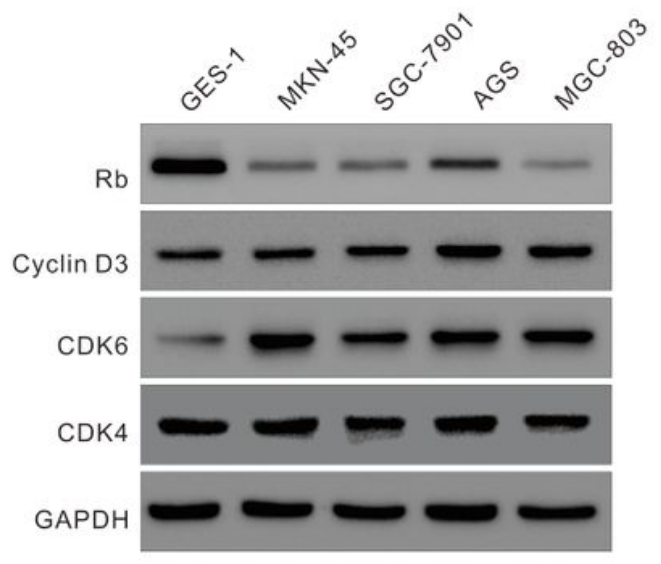

Figure 1

Expression levels of Cyclin D3-CDK6 complex in gastric cancer tissues and gastric cancer cell line. (A) Immunohistochemical analysis of Cyclin D3-CDK6 complex protein levels in gastric cancer tissue pairs. (B and C) Statistical analysis of the immunohistochemical scores (C) Pearson's correlation scatter plot of Cyclin D3 and CDK6 expression level in gastric cancer tissues. (E and F) Kaplan-Meier curves of gastric cancer with low expression versus high expression of Cyclin D3 or CDK6 ( $n=92)$. (G) Western blotting analysis of the expression level of Cyclin D3 or CDK6 in 15 pairs of gastric cancer tissues. $(H)$ Western 
blot analysis of Rb, Cyclin D3, CDK6 and CDK4 levels in 4 gastric cancer cell lines and 1 human gastric epithelial cell line. ${ }^{* \star *} \mathrm{P}<0.001$.

A

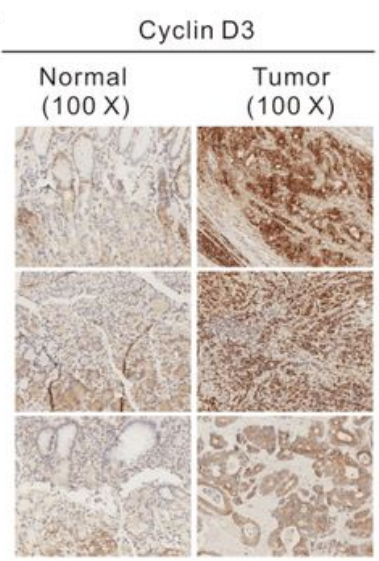

D

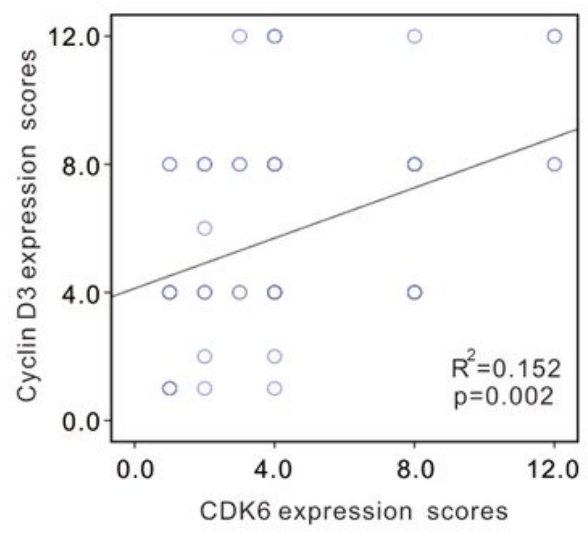

G
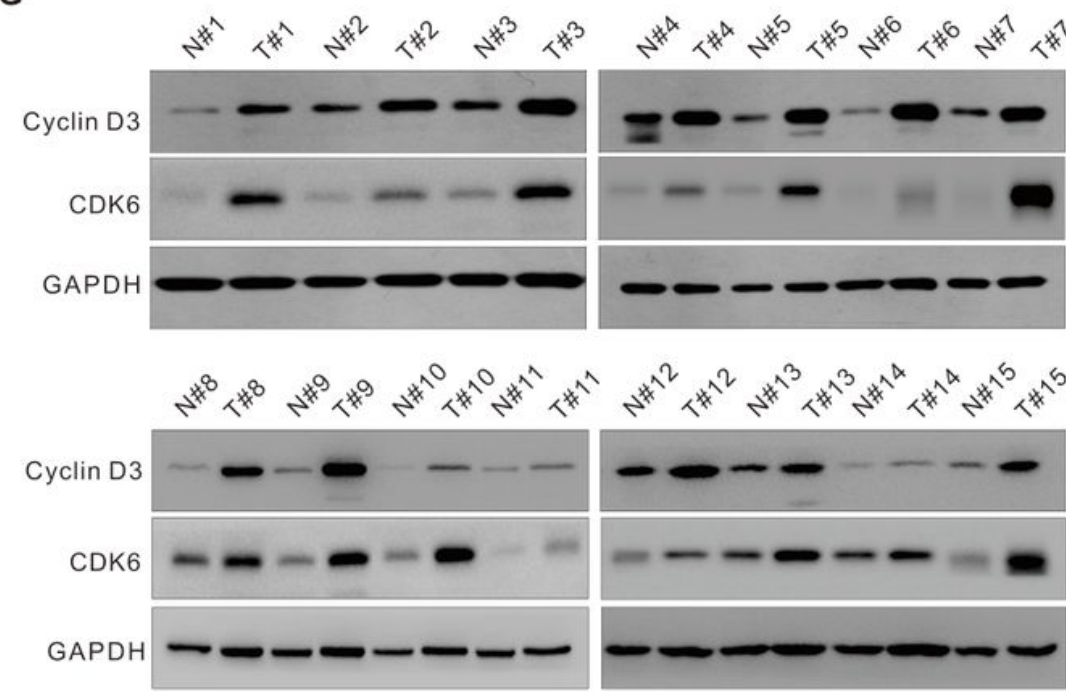

B

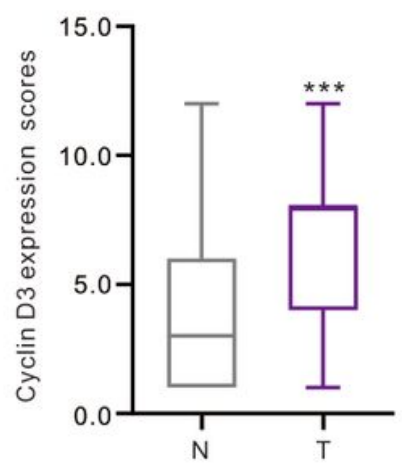

Cyclin D3

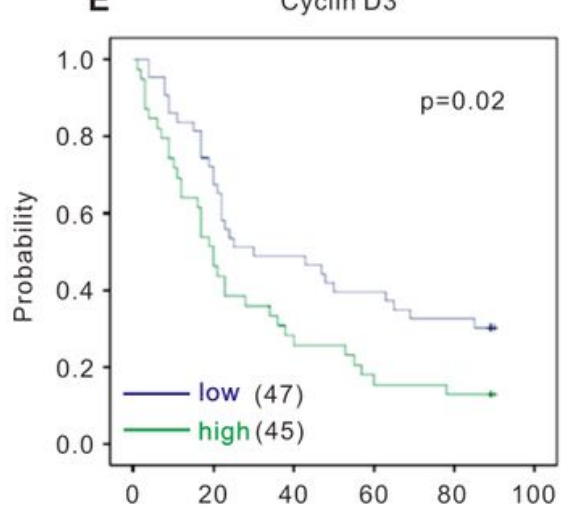

C

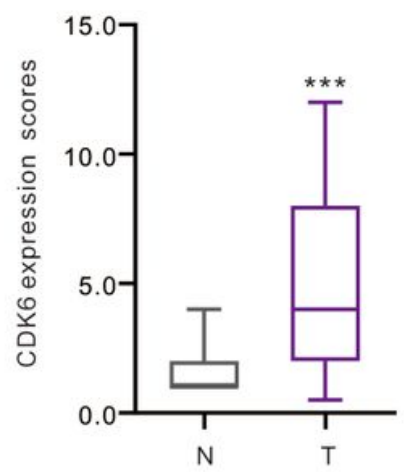

F

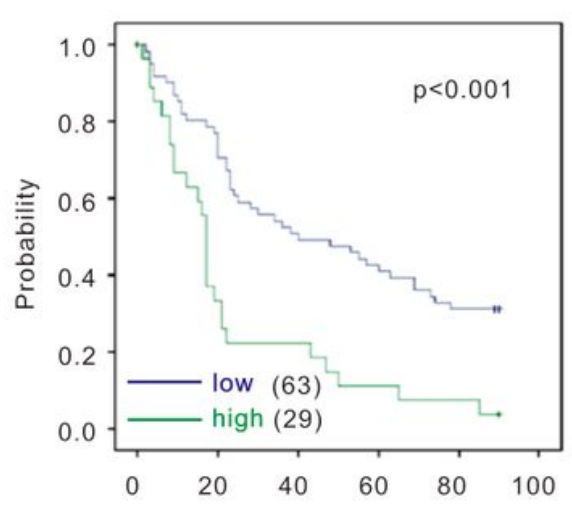

$\mathrm{H}$

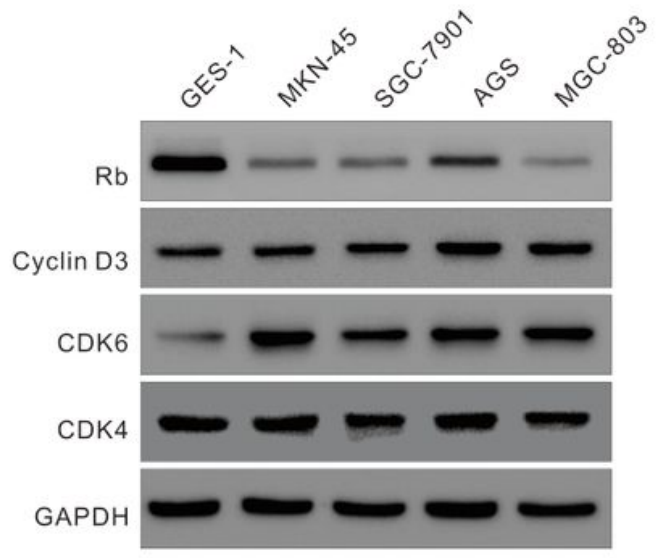

Figure 1

Expression levels of Cyclin D3-CDK6 complex in gastric cancer tissues and gastric cancer cell line. (A) Immunohistochemical analysis of Cyclin D3-CDK6 complex protein levels in gastric cancer tissue pairs. (B and C) Statistical analysis of the immunohistochemical scores (C) Pearson's correlation scatter plot of Cyclin D3 and CDK6 expression level in gastric cancer tissues. (E and F) Kaplan-Meier curves of gastric 
cancer with low expression versus high expression of Cyclin D3 or CDK6 ( $\mathrm{n}=92)$. (G) Western blotting analysis of the expression level of Cyclin D3 or CDK6 in 15 pairs of gastric cancer tissues. $(H)$ Western blot analysis of Rb, Cyclin D3, CDK6 and CDK4 levels in 4 gastric cancer cell lines and 1 human gastric epithelial cell line. ${ }^{\star * *} \mathrm{P}<0.001$.
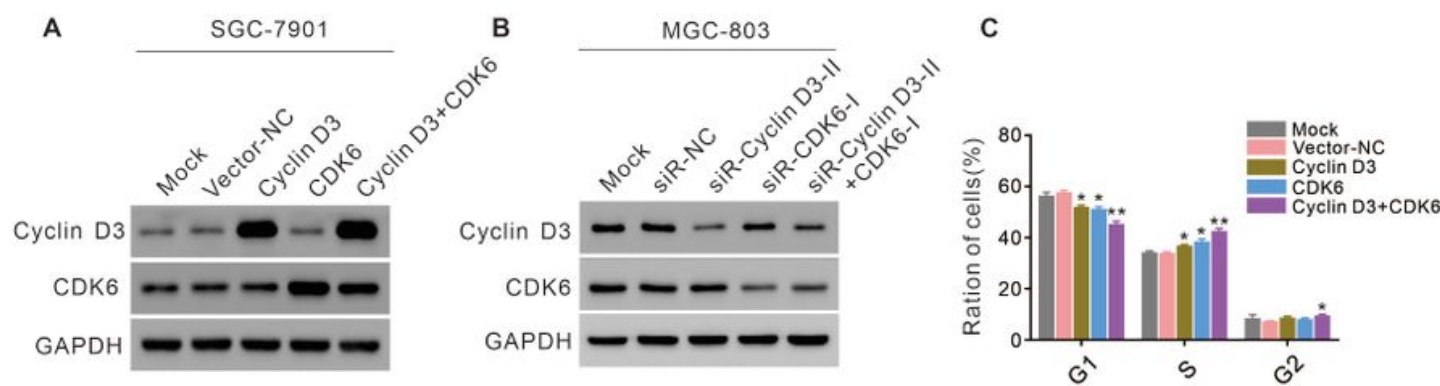

D
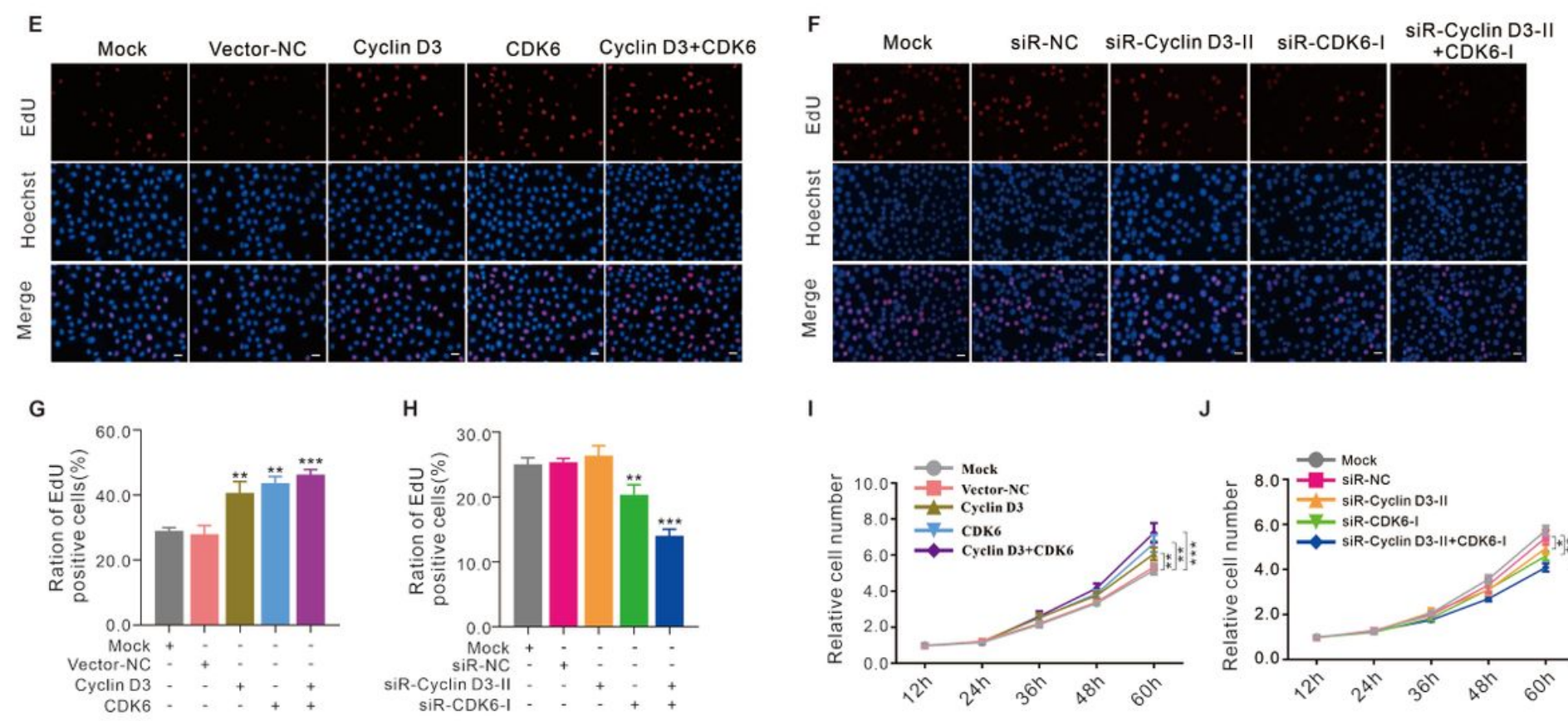

I

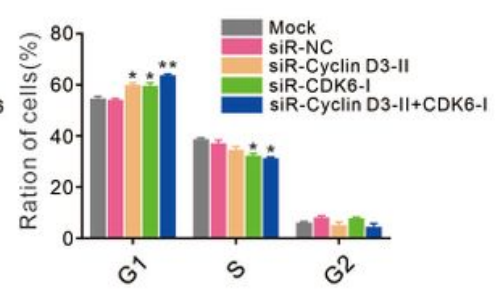

\section{Figure 2}

Cyclin D3-CDK6 complex promoted gastric cancer cell proliferation in vitro. (A) Western blotting analysis of Cyclin D3 and CDK6 protein levels in SGC-7901 transfected with Cyclin D3 and CDK6 overexpression plasmid. (B) Western blotting analysis of Cyclin D3 and CDK6 protein levels in MGC-803 cells transfected with Cyclin D3 and CDK6 siRNA. (C and D) Cell cycle distribution were analyzed using flow cytometry after the transfected with Cyclin D3 and CDK6 overexpression plasmid and siRNA. (E-H) Cell proliferation was evaluated by EdU assay. (E and F) Representative images, Scale bar = $25 \mu \mathrm{m}$; (G and H) Quantitative analysis of EdU-positive cells. (I and J) Cell proliferation was evaluated by CCK8 assay. ${ }^{*} \mathrm{P}<0.05$; ${ }^{\star *} \mathrm{P}<$ $0.01 ; * \star * P<0.001$. 


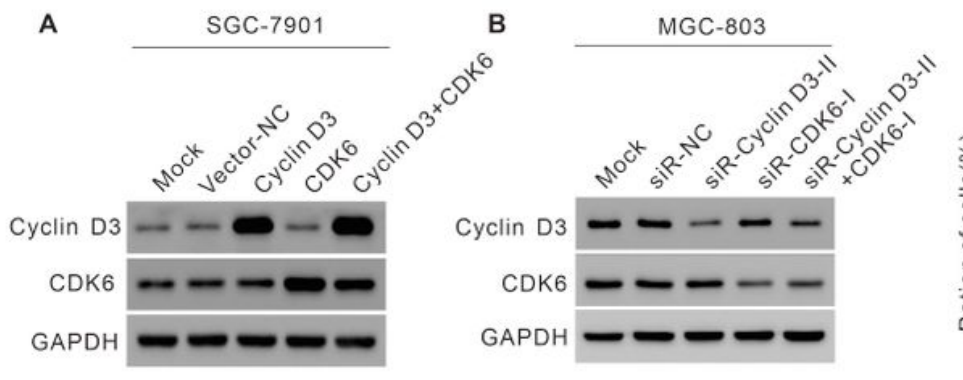

C
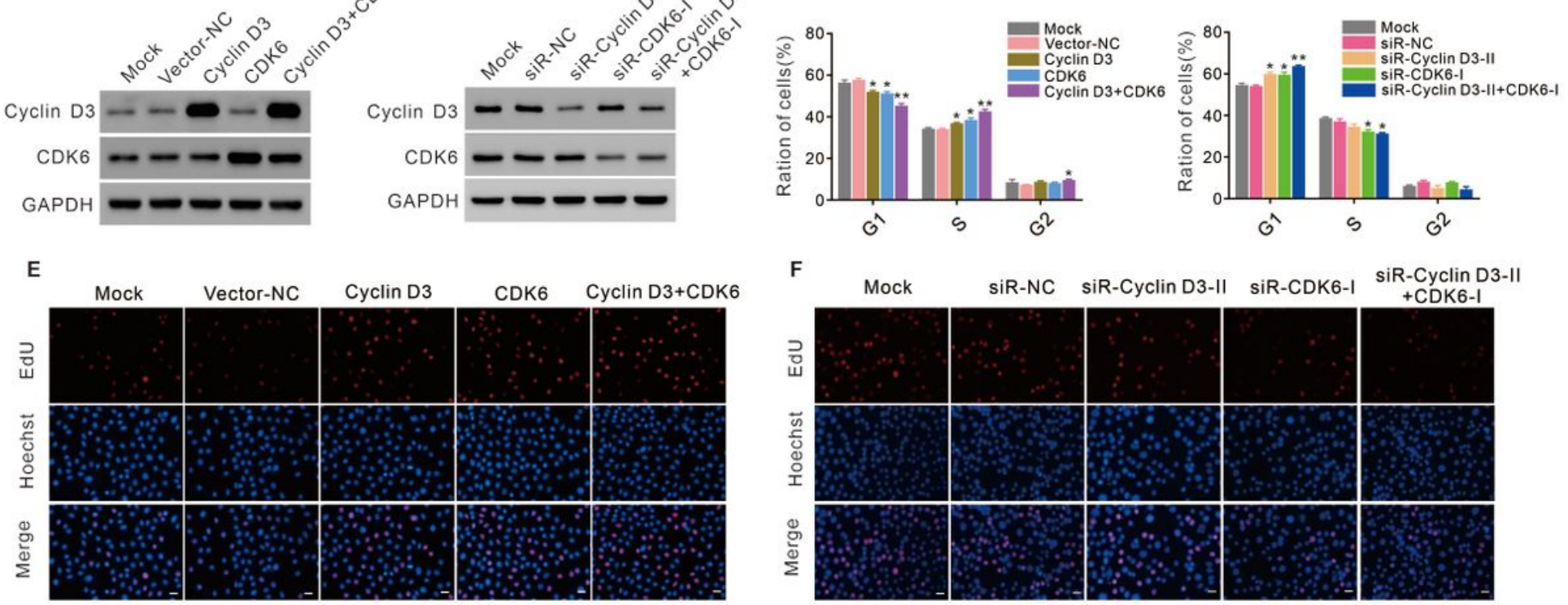

G

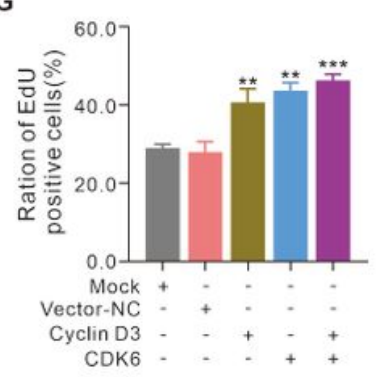

H

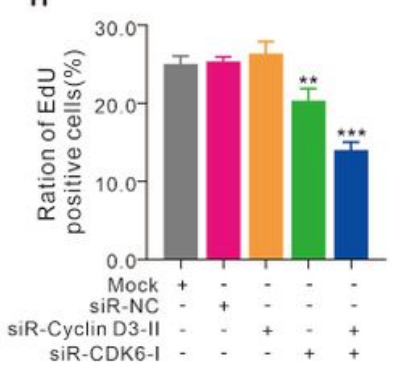

।

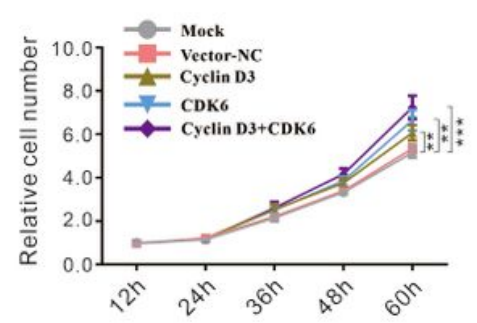

J

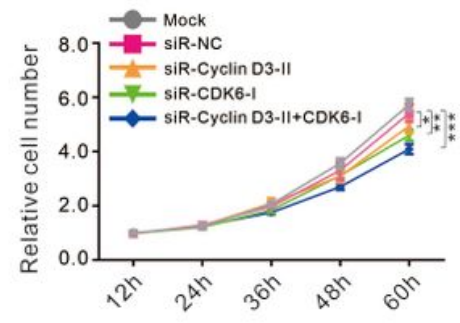

Figure 2

Cyclin D3-CDK6 complex promoted gastric cancer cell proliferation in vitro. (A) Western blotting analysis of Cyclin D3 and CDK6 protein levels in SGC-7901 transfected with Cyclin D3 and CDK6 overexpression plasmid. (B) Western blotting analysis of Cyclin D3 and CDK6 protein levels in MGC-803 cells transfected with Cyclin D3 and CDK6 siRNA. (C and D) Cell cycle distribution were analyzed using flow cytometry after the transfected with Cyclin D3 and CDK6 overexpression plasmid and siRNA. (E-H) Cell proliferation was evaluated by EdU assay. ( $E$ and F) Representative images, Scale bar $=25 \mu \mathrm{m}$; ( $G$ and $H$ ) Quantitative analysis of EdU-positive cells. (I and J) Cell proliferation was evaluated by CCK8 assay. ${ }^{*} P<0.05 ; * \star P<$ $0.01 ; * \star \star P P<0.001$. 

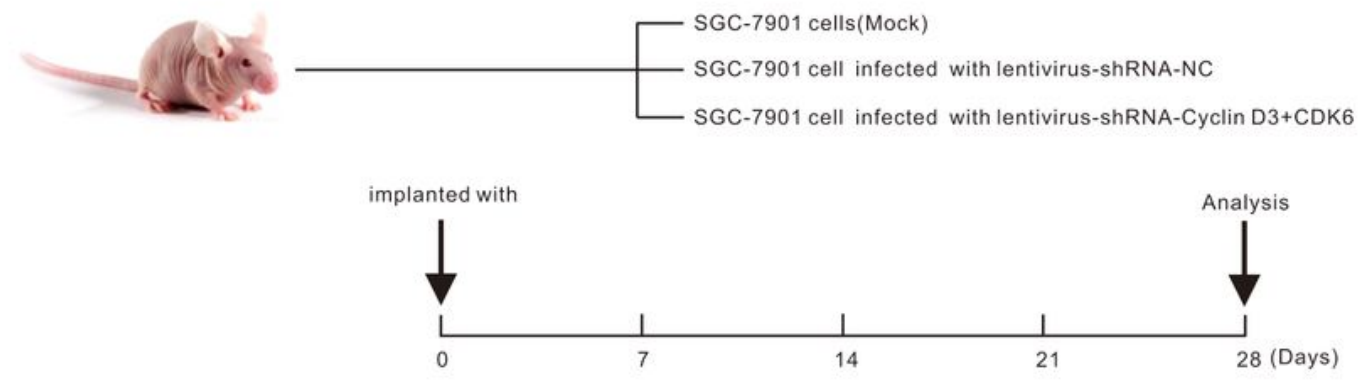

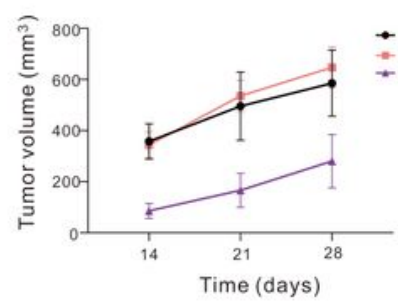

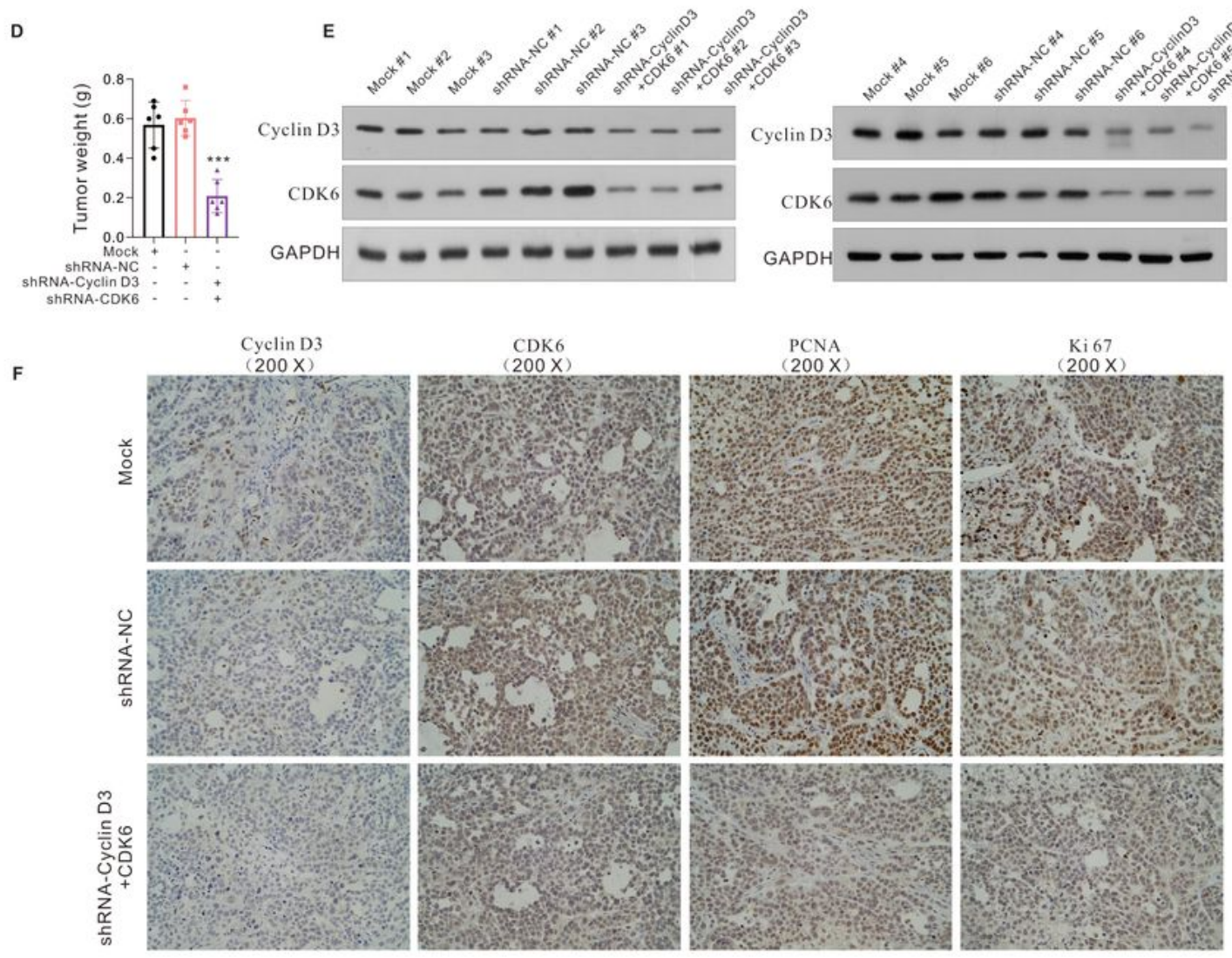

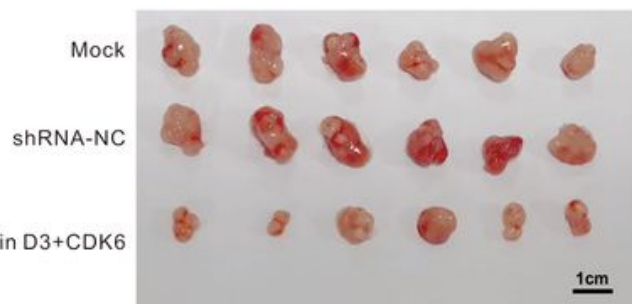

\section{Figure 3}

Cyclin D3-CDK6 complex accelerated xenografte tumor growth in vivo (A) A flow chart demonstrating the in vivo experimental design. (B) Dynamic quantitative analysis of tumor volume. (C) Images of xenograft tumors excised from nude mice (D) The quantitative analysis of tumor weight. (E) Western blotting analysis of Cyclin D3 and CDK6 expression levels in the tumors from implanted mice. (F) Immunohistochemical analysis of Cyclin D3, CDK6, PCNA and Ki67 expression in xenograft tumors. 

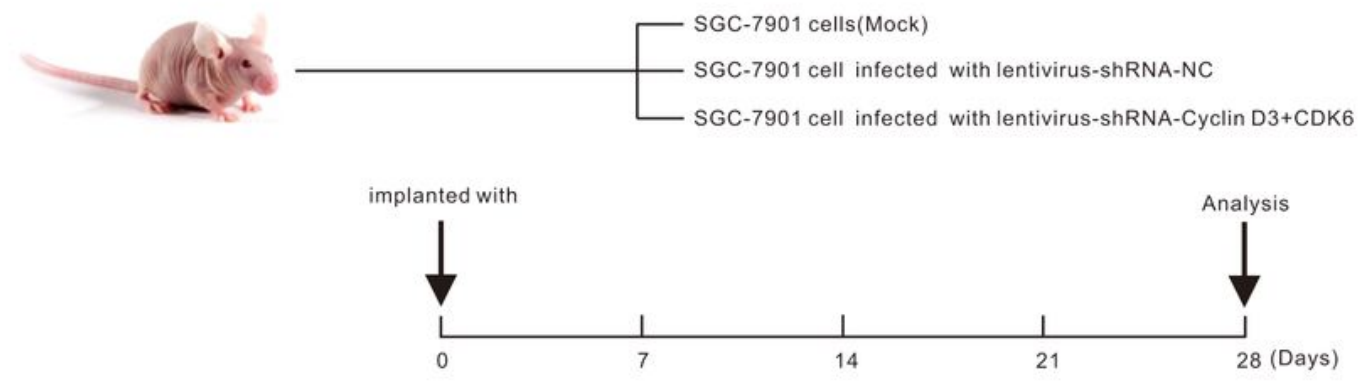

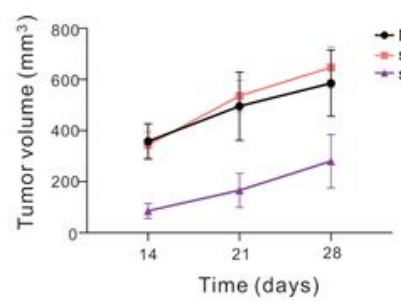

E

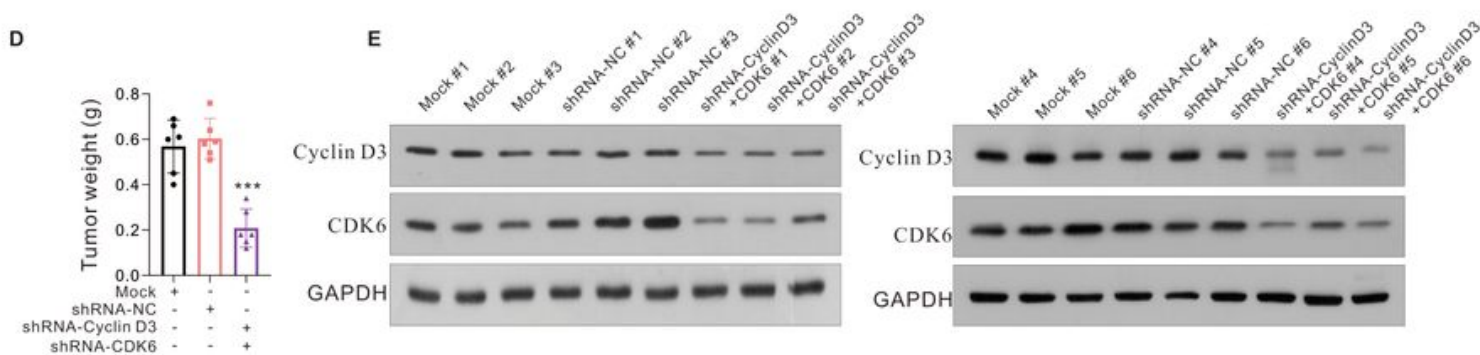

$\mathbf{F}$
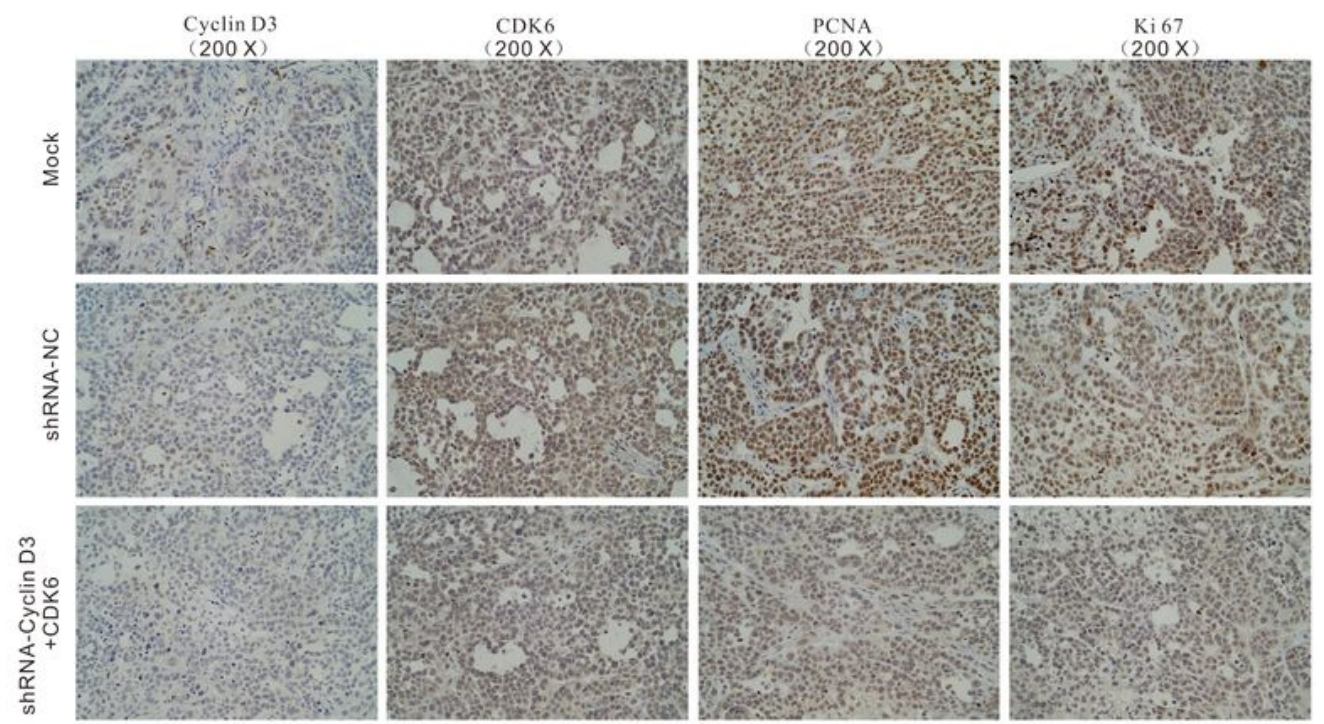

\section{Figure 3}

Cyclin D3-CDK6 complex accelerated xenografte tumor growth in vivo (A) A flow chart demonstrating the in vivo experimental design. (B) Dynamic quantitative analysis of tumor volume. (C) Images of xenograft tumors excised from nude mice (D) The quantitative analysis of tumor weight. (E) Western blotting analysis of Cyclin D3 and CDK6 expression levels in the tumors from implanted mice. (F) Immunohistochemical analysis of Cyclin D3, CDK6, PCNA and Ki67 expression in xenograft tumors. 


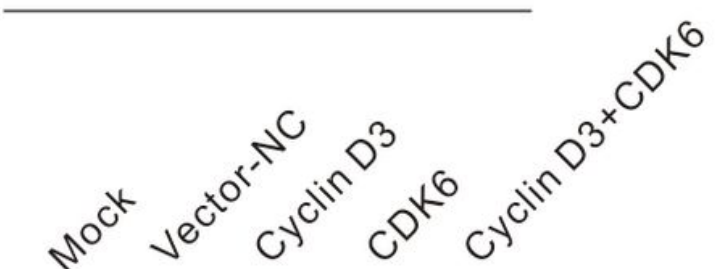

pRb (Ser 807/811)

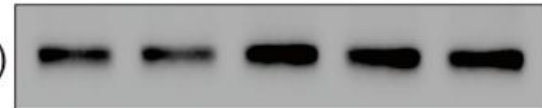

pRb (Ser 807/811)
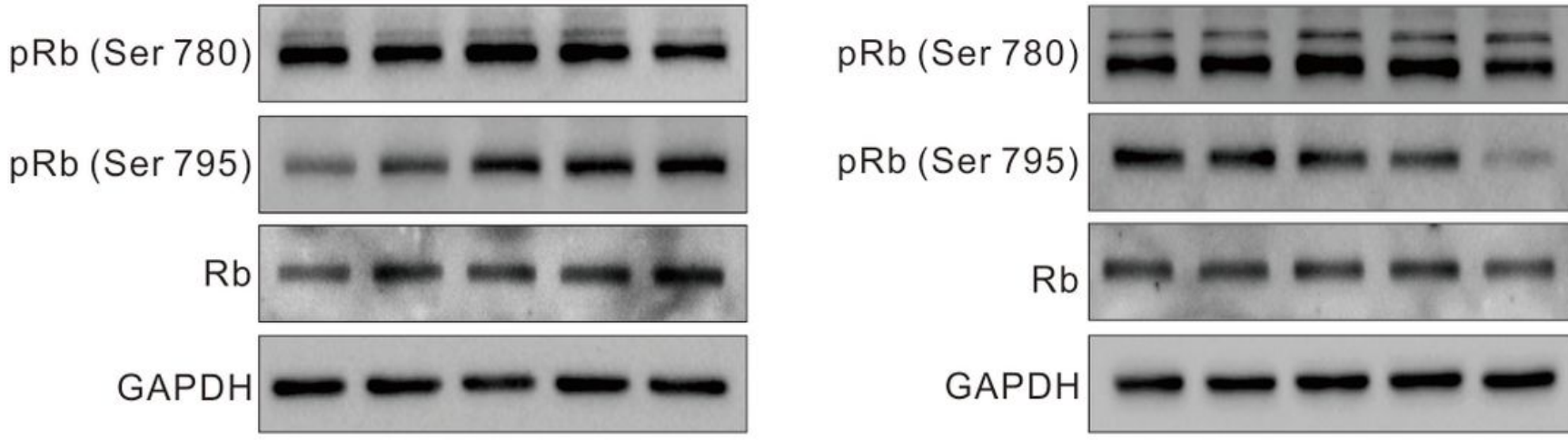

pRb (Ser 795)
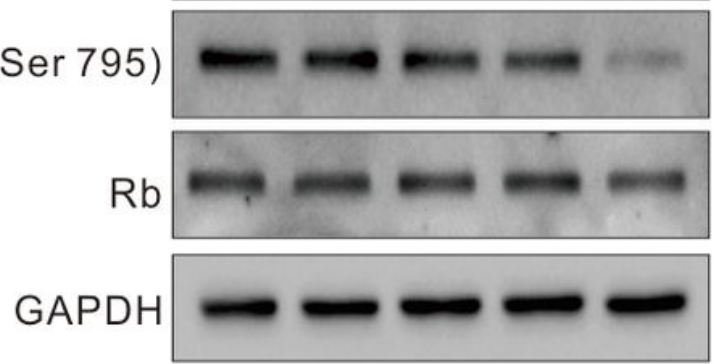

C

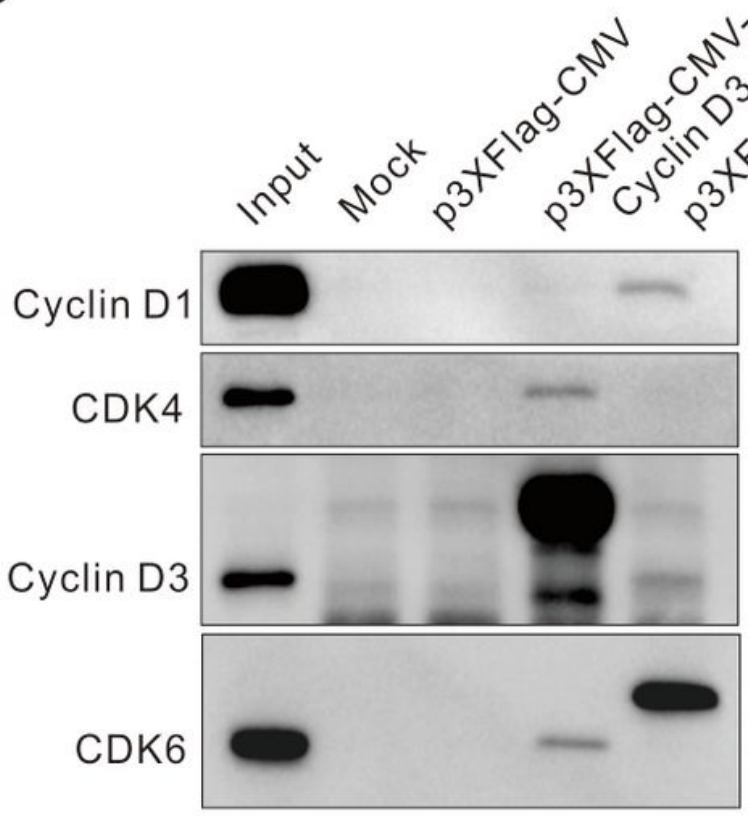

D
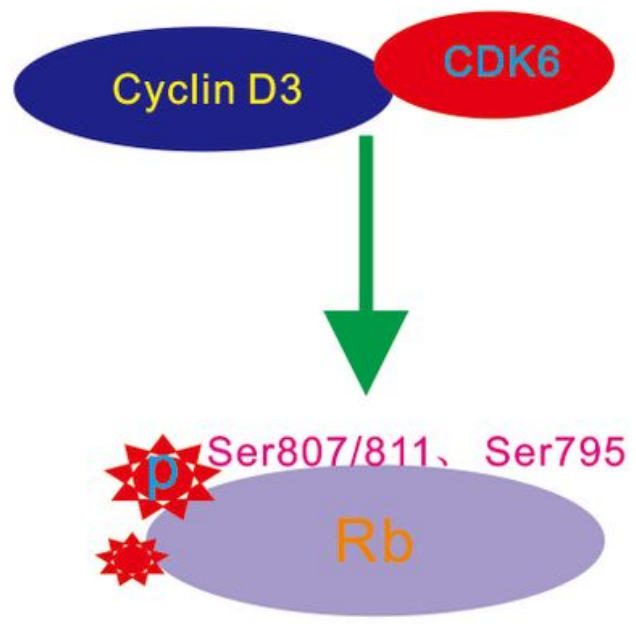

\section{Figure 4}

Cyclin D3-CDK6 complex mediated the phosphorylation of Rb. (A) Western blotting analysis of Rb and pRb levels in SGC-7901 cells transfected with Cyclin D3 and CDK6 overexpression plasmid. (B) Western blotting analysis of Rb and pRb levels in MGC-803 cells transfected with Cyclin D3 and CDK6 siRNA. (C)SGC-7901 cells transfected with Flag-tagged Cyclin D3 or Flag-tagged CDK6 overexpression plasmid, and total protein extracts were subjected to Co-IP using anti-Flag antibody, followed by Western blot 
analysis. (D) Working Model for Cyclin D3-CDK6 complex mediates Rb phosphorylation at two serine sites (S795 and S807/811).

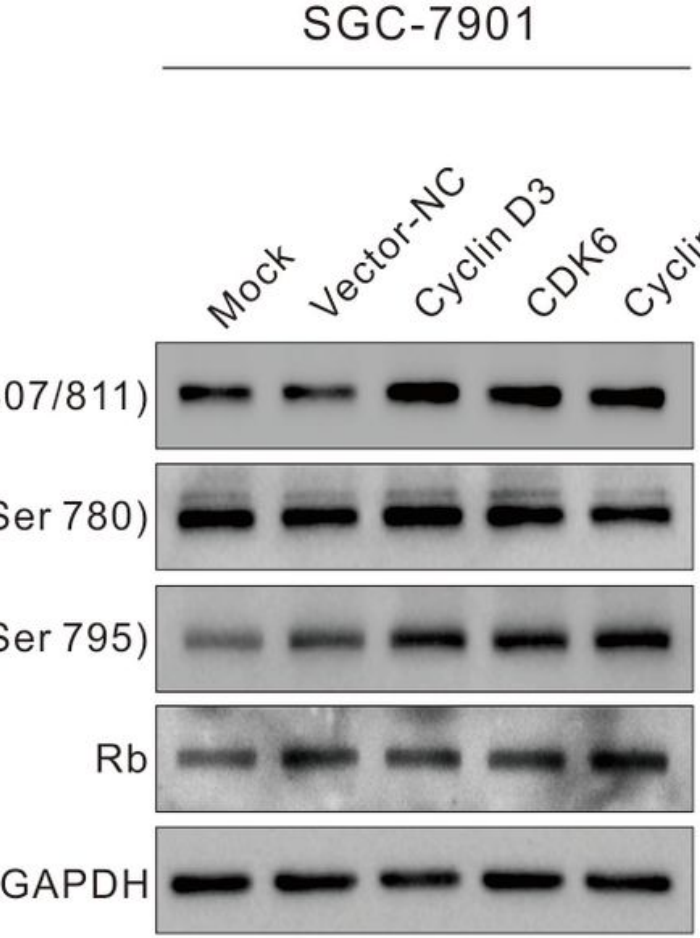

C

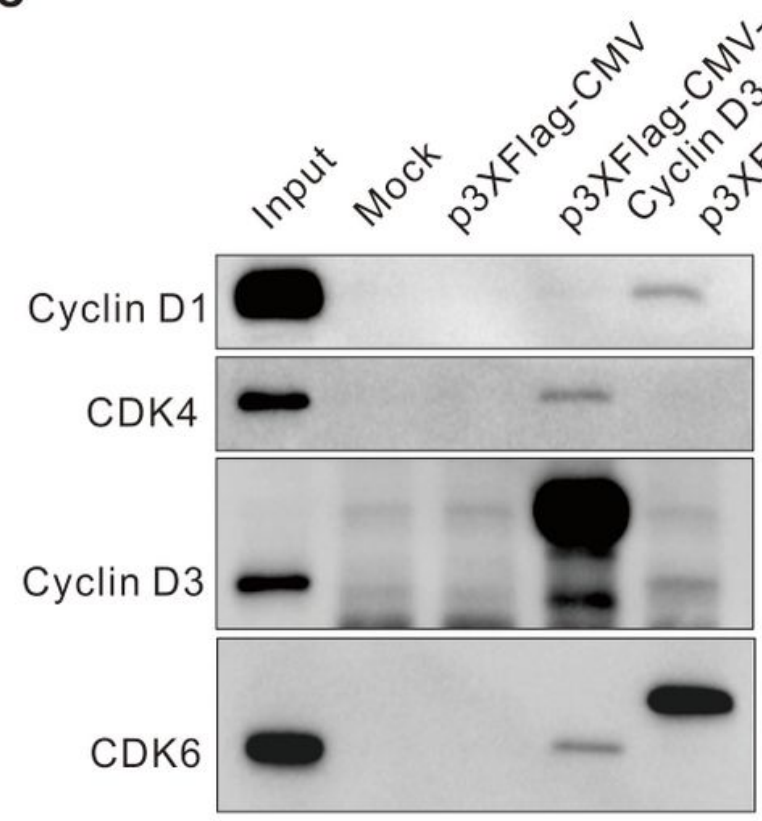

\section{GAPDH}

A

B MGC-803

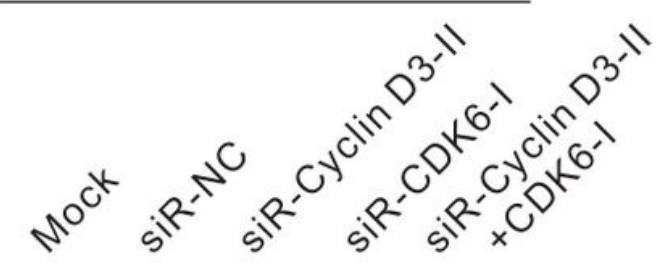

$\mathrm{pRb}($ Ser 807/811)

pRb (Ser 780)

$\mathrm{pRb}(\operatorname{Ser} 795)$

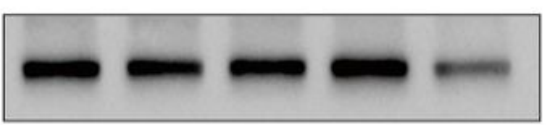

pRb (Ser 780)

$\mathrm{pRb}($ Ser 795)

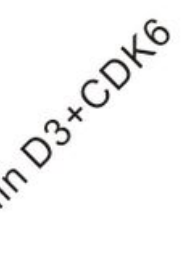

D
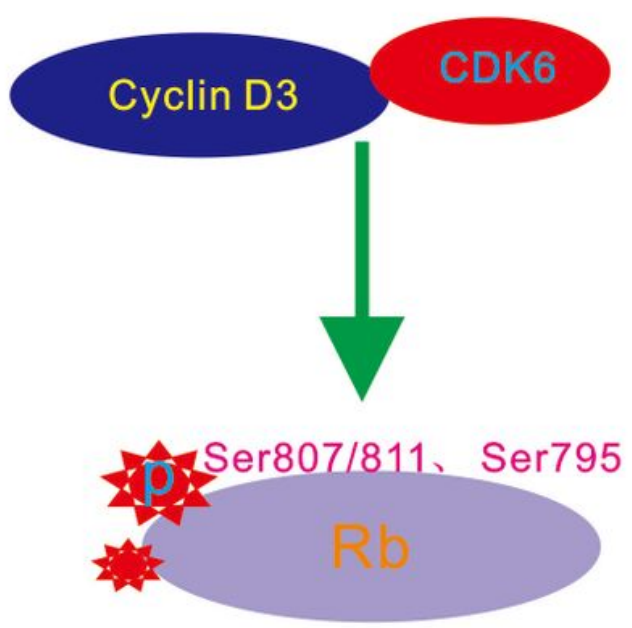

\section{Figure 4}

Cyclin D3-CDK6 complex mediated the phosphorylation of Rb. (A) Western blotting analysis of Rb and pRb levels in SGC-7901 cells transfected with Cyclin D3 and CDK6 overexpression plasmid. (B) Western blotting analysis of Rb and pRb levels in MGC-803 cells transfected with Cyclin D3 and CDK6 siRNA. (C)SGC-7901 cells transfected with Flag-tagged Cyclin D3 or Flag-tagged CDK6 overexpression plasmid, 
and total protein extracts were subjected to Co-IP using anti-Flag antibody, followed by Western blot analysis. (D) Working Model for Cyclin D3-CDK6 complex mediates Rb phosphorylation at two serine sites (S795 and S807/811).

A

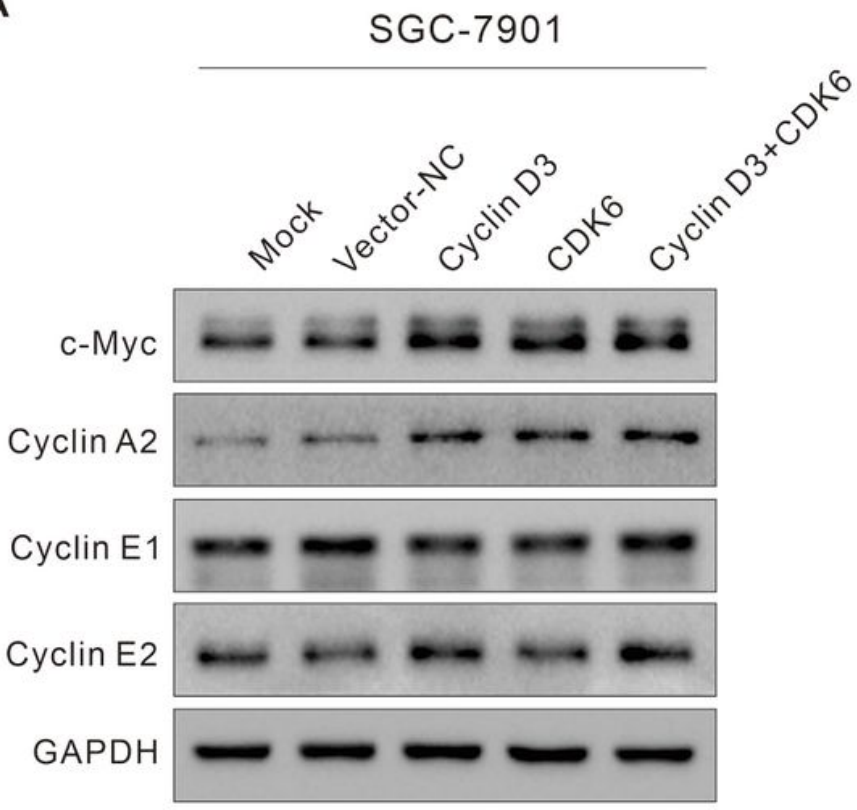

B

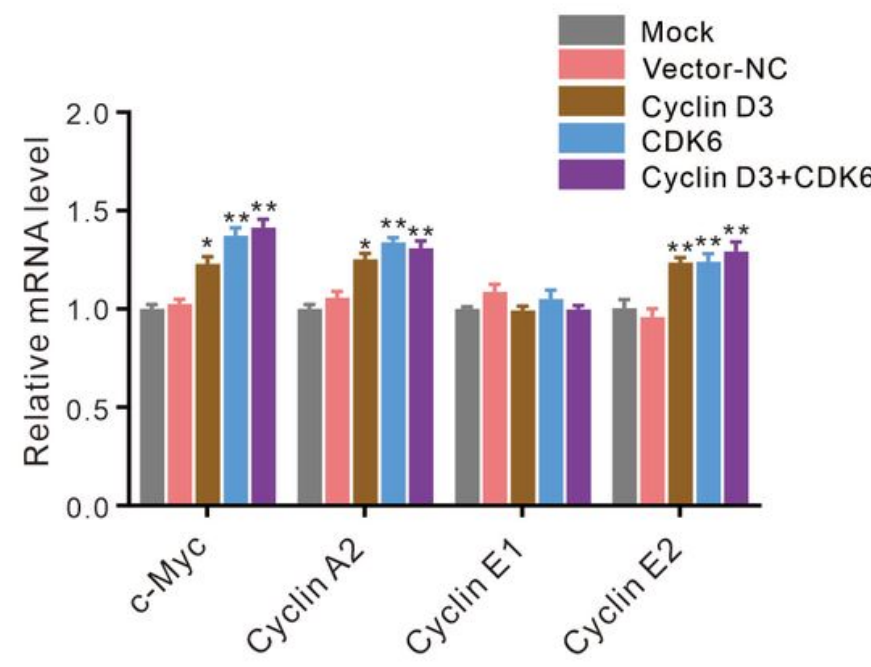

C MGC-803

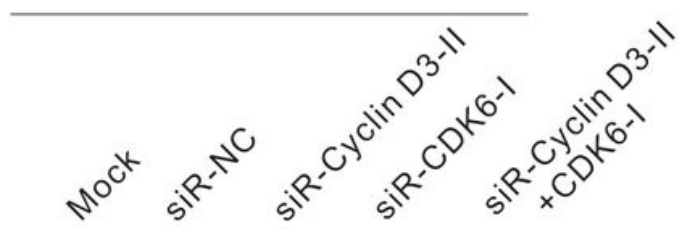

C-Myc

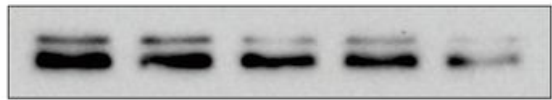

Cyclin A2

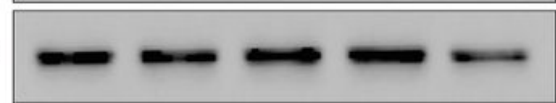

Cyclin E1

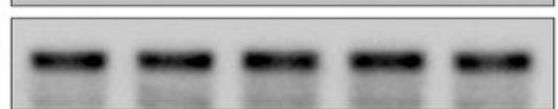

Cyclin E2

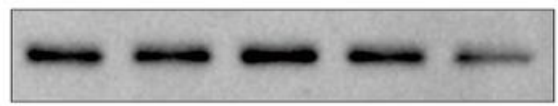

GAPDH

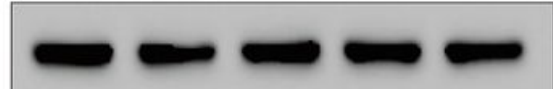

D

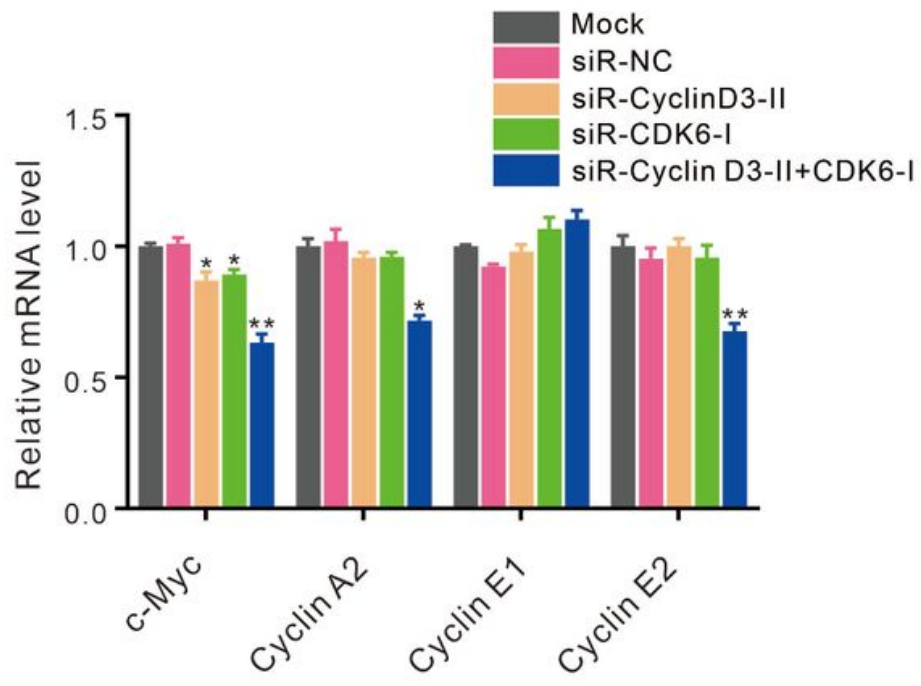

\section{Figure 5}

Cyclin D3-CDK6 complex facilitated the expression of downstream genes. (A and C) Western blotting analysis of protein levels of c-Myc, Cyclin A2, Cyclin E1 and Cyclin E2. (B and D) Quantitative RT-PCR analysis of mRNA expression levels of c-Myc, Cyclin A2, Cyclin E1 and Cyclin E2. (A and B) SGC-7901 cells transfected with Cyclin D3 and CDK6 overexpression plasmid. (C and D) MGC-803 cells transfected with Cyclin D3 and CDK6 siRNA. ${ }^{*} P<0.05 ;{ }^{*} \mathrm{P}<0.01$. 
A

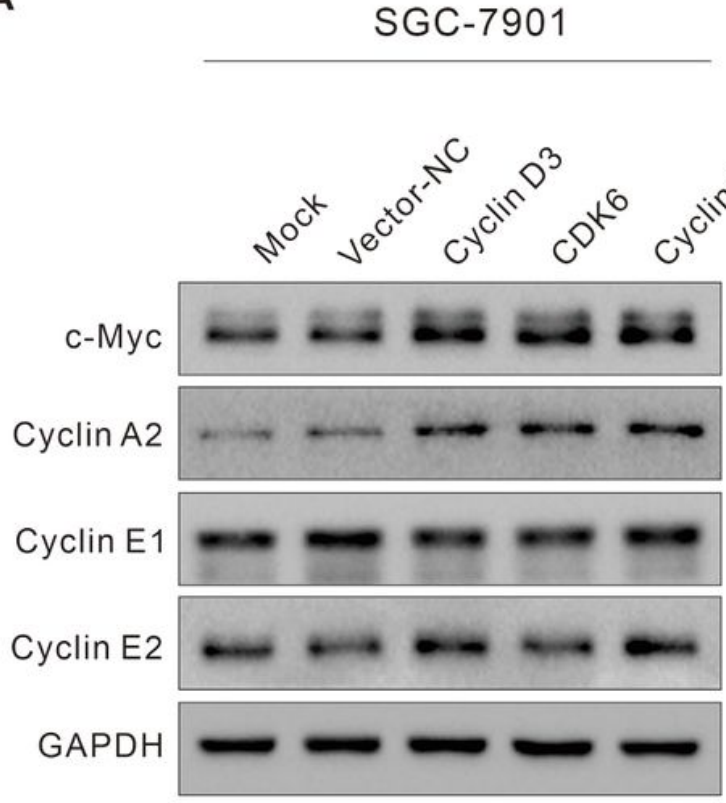

C

MGC-803
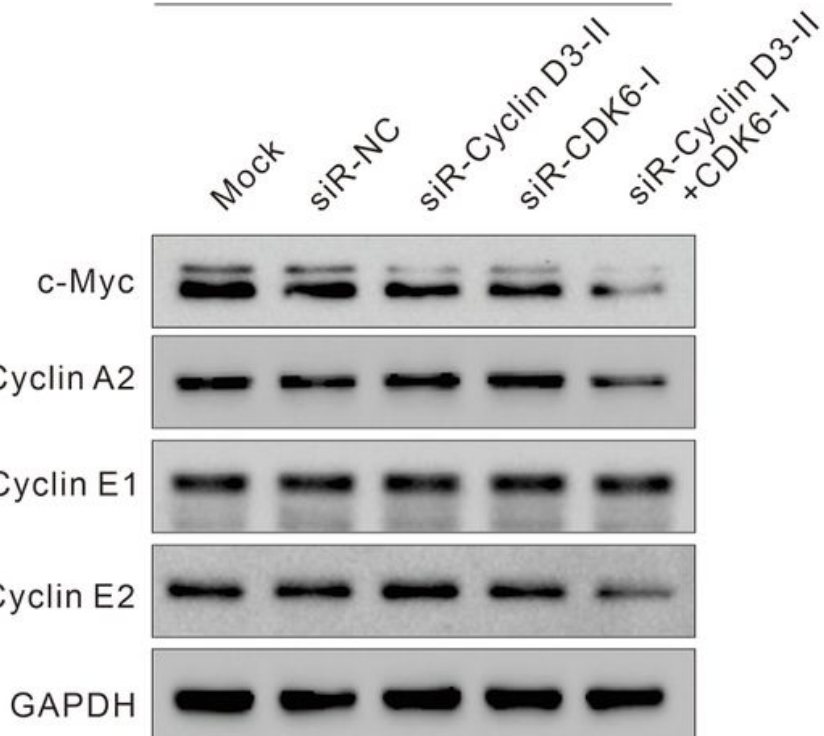

D

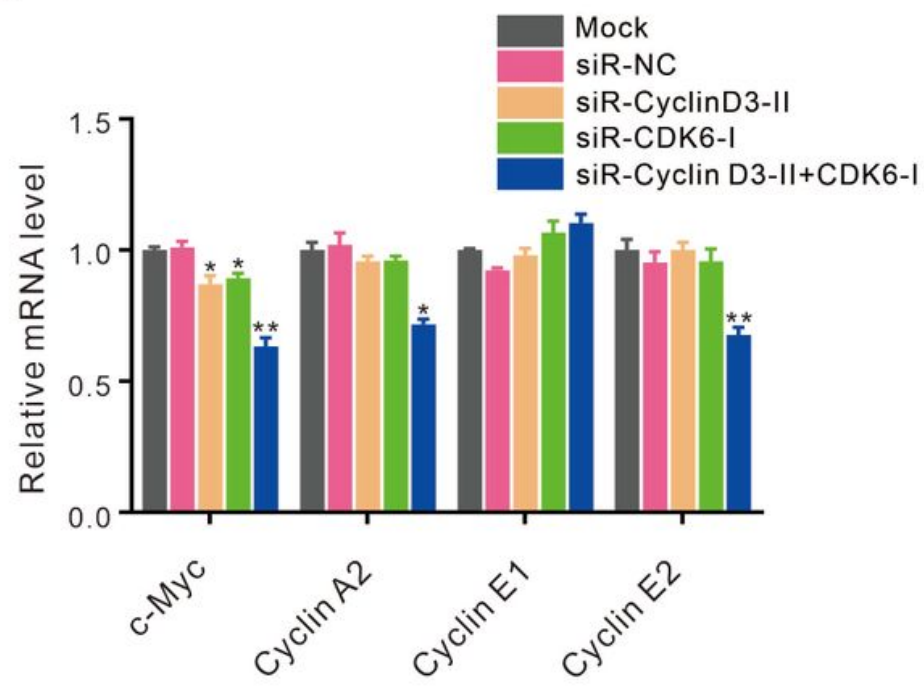

\section{Figure 5}

Cyclin D3-CDK6 complex facilitated the expression of downstream genes. (A and C) Western blotting analysis of protein levels of c-Myc, Cyclin A2, Cyclin E1 and Cyclin E2. (B and D) Quantitative RT-PCR analysis of mRNA expression levels of c-Myc, Cyclin A2, Cyclin E1 and Cyclin E2. (A and B) SGC-7901 cells transfected with Cyclin D3 and CDK6 overexpression plasmid. (C and D) MGC-803 cells transfected with Cyclin D3 and CDK6 siRNA. *P<0.05; ** $\mathrm{P}<0.01$. 
A

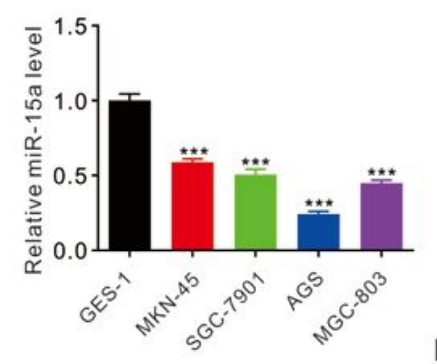

E

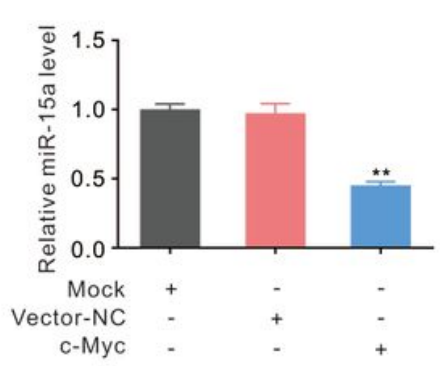

I

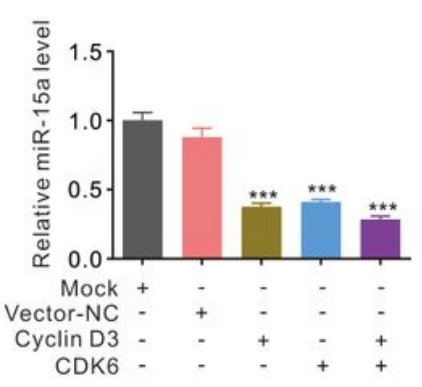

B
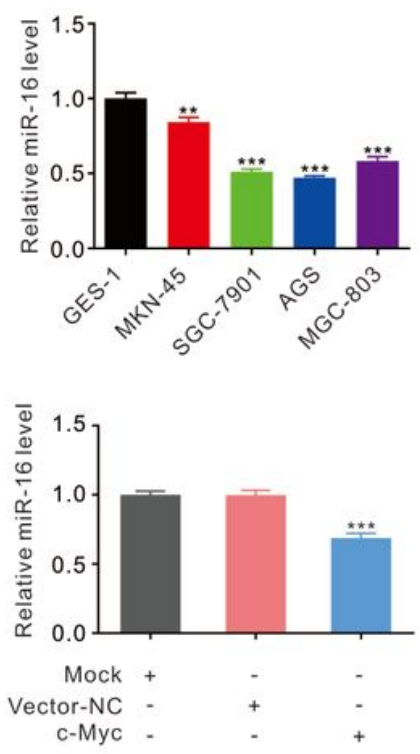

J

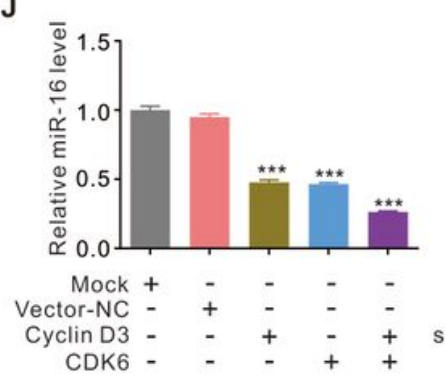

C

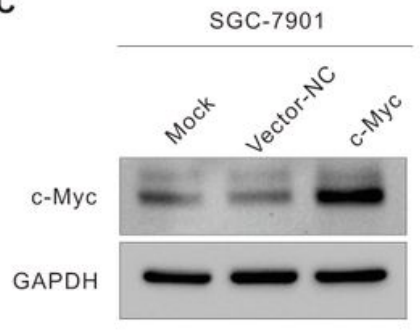

G

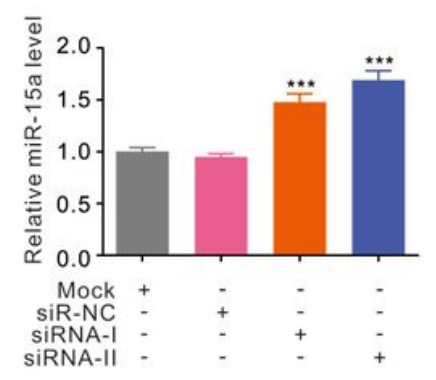

$\mathrm{K}_{-}$

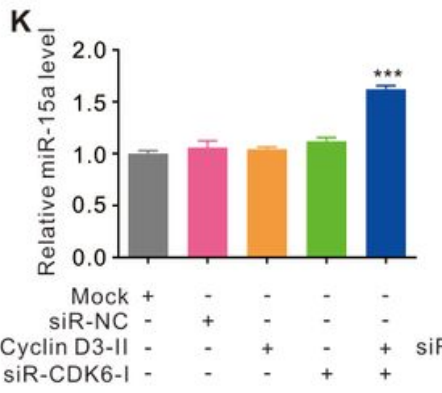

D

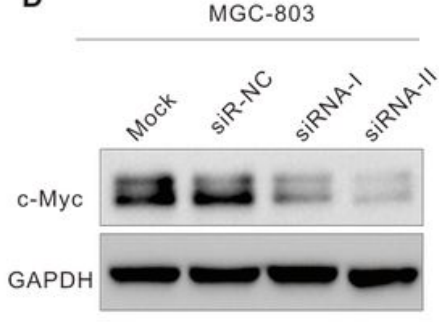

H
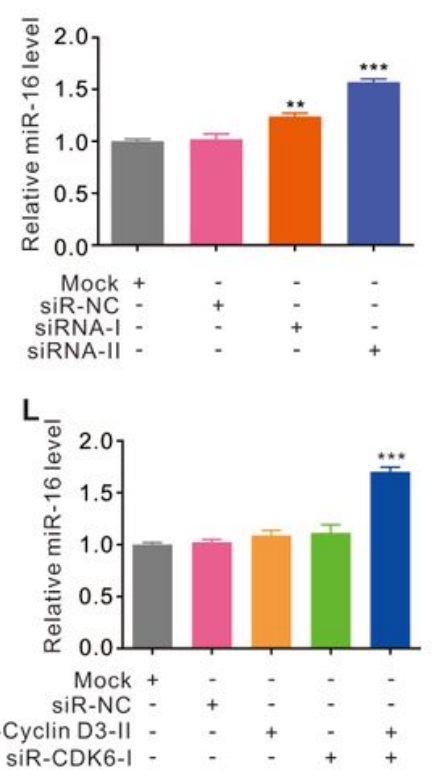
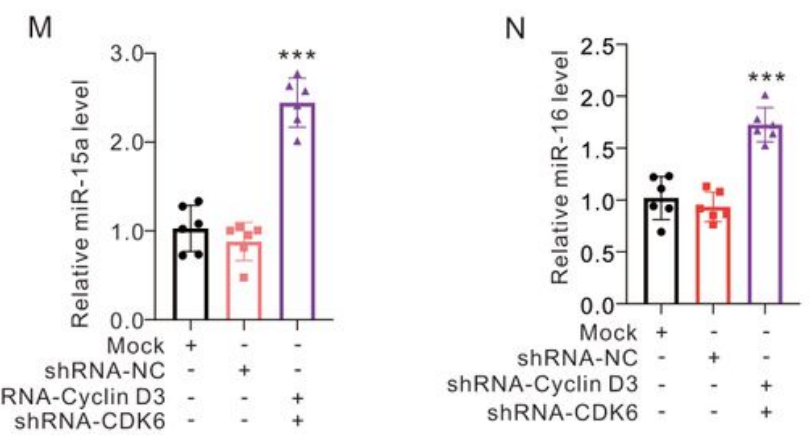

\section{Figure 6}

Cyclin D3-CDK6 complex suppressed miR-15a/16 expression by inducing c-Myc overexpression. (A and B) Quantitative RT-PCR analysis of expression levels of miR-15a and miR-16 in cell lines. (C) Western blotting analysis of c-Myc protein levels in SGC-7901 cells transfected with c-Myc overexpression plasmid. (D) Western blotting analysis of c-Myc protein levels in MGC-803 cells transfected with c-Myc siRNAs. (E and F) Quantitative RT-PCR analysis of the expression levels of miR-15a and miR-16 in SGC7901 cells transfected with c-Myc overexpression plasmid. ( $G$ and H) Quantitative RT-PCR analysis of the expression levels of miR-15a and miR-16 in MGC-803 cells transfected with c-Myc siRNAs. (I and J) Quantitative RT-PCR analysis of the expression levels of miR-15a and miR-16 in SGC-7901 cells transfected with Cyclin D3 and CDK6 overexpression plasmid. (K and L) Quantitative RT-PCR analysis of 
the expression levels of miR-15a and miR-16 in MGC-803 cells transfected with Cyclin D3 and CDK6 siRNAs. (M and N) Quantitative RT-PCR analysis of the expression levels of miR-15a and miR-16 in the tumors from implanted mice. ${ }^{* *} \mathrm{P}<0.01 ;{ }^{* * *} \mathrm{P}<0.001$.

E
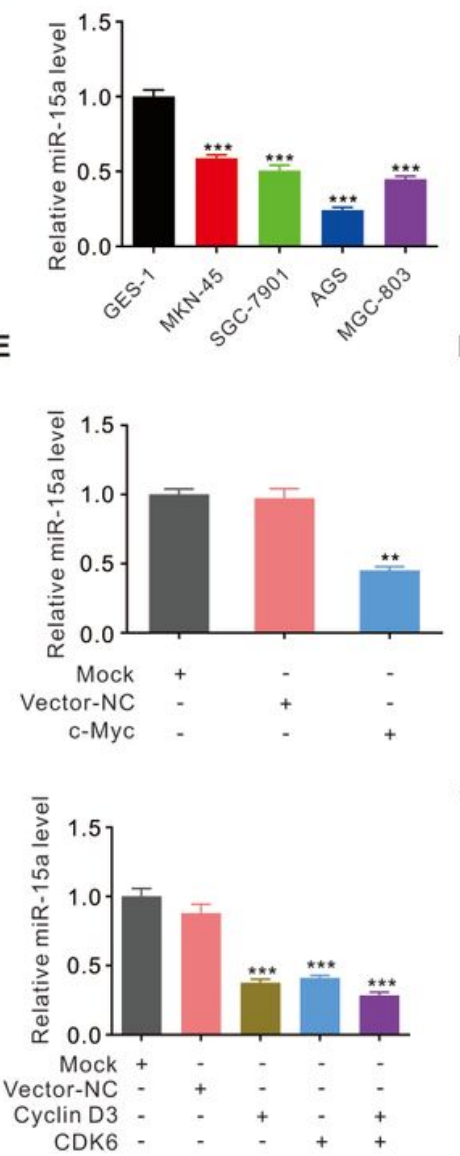

B
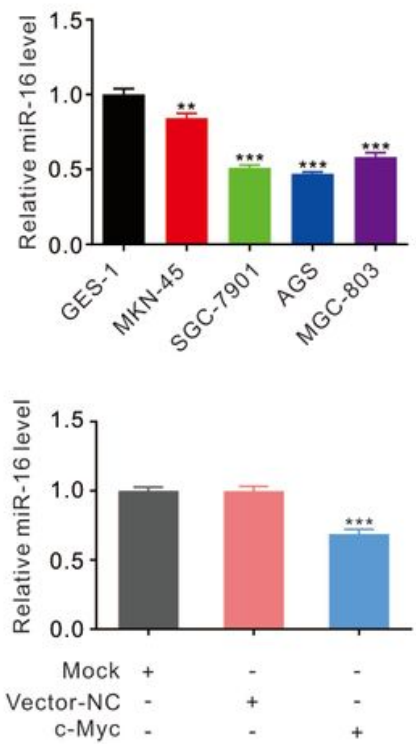

$J$

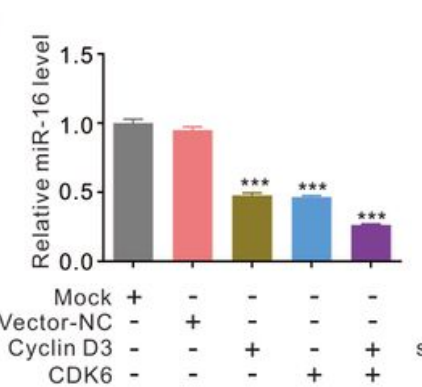

C

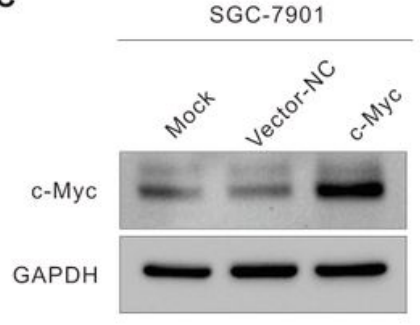

G

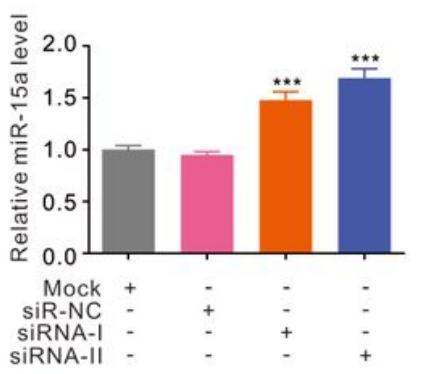

$\mathrm{K}$

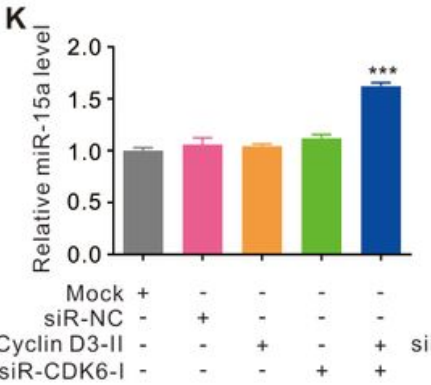

D

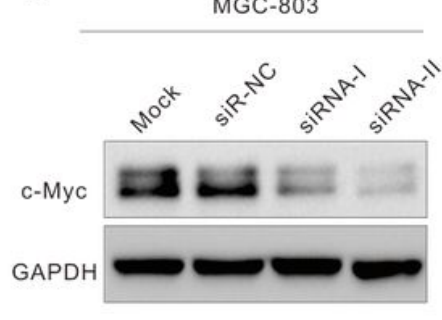

H
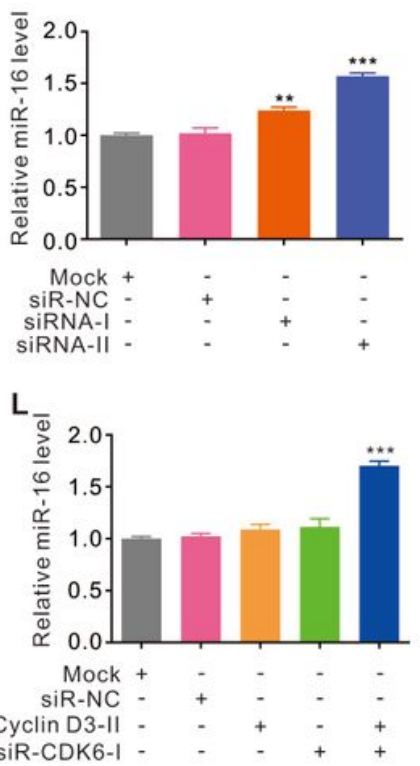

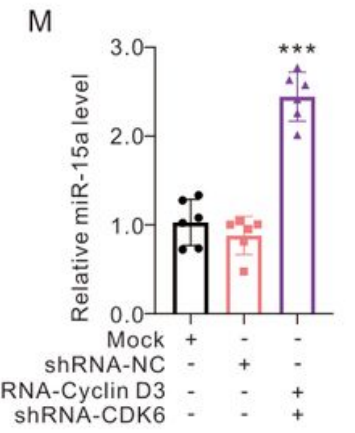

N

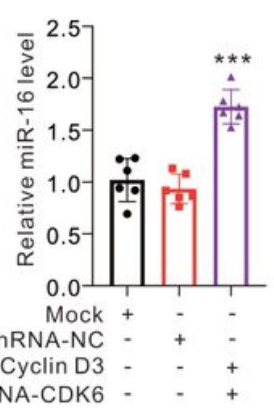

\section{Figure 6}

Cyclin D3-CDK6 complex suppressed miR-15a/16 expression by inducing c-Myc overexpression. (A and B) Quantitative RT-PCR analysis of expression levels of miR-15a and miR-16 in cell lines. (C) Western blotting analysis of c-Myc protein levels in SGC-7901 cells transfected with c-Myc overexpression plasmid. (D) Western blotting analysis of c-Myc protein levels in MGC-803 cells transfected with c-Myc siRNAs. (E and F) Quantitative RT-PCR analysis of the expression levels of miR-15a and miR-16 in SGC7901 cells transfected with c-Myc overexpression plasmid. ( $G$ and H) Quantitative RT-PCR analysis of the 
expression levels of miR-15a and miR-16 in MGC-803 cells transfected with c-Myc siRNAs. (I and $\mathrm{J}$ ) Quantitative RT-PCR analysis of the expression levels of miR-15a and miR-16 in SGC-7901 cells transfected with Cyclin D3 and CDK6 overexpression plasmid. ( $K$ and L) Quantitative RT-PCR analysis of the expression levels of miR-15a and miR-16 in MGC-803 cells transfected with Cyclin D3 and CDK6 siRNAs. ( $M$ and $N$ ) Quantitative RT-PCR analysis of the expression levels of miR-15a and miR-16 in the tumors from implanted mice. ${ }^{* *} \mathrm{P}<0.01 ; * * * \mathrm{P}<0.001$.

A

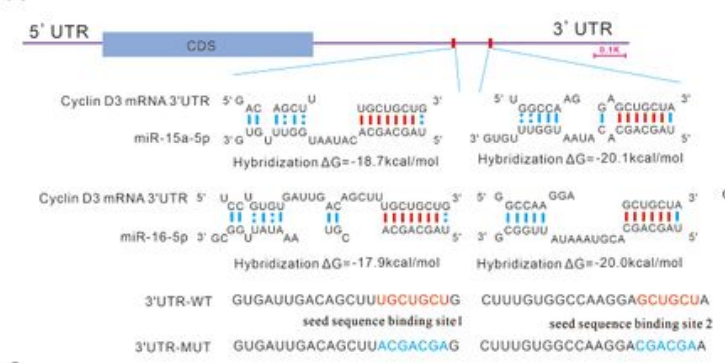

c

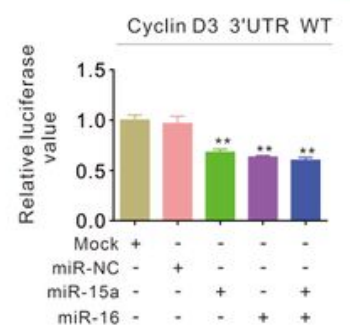

E
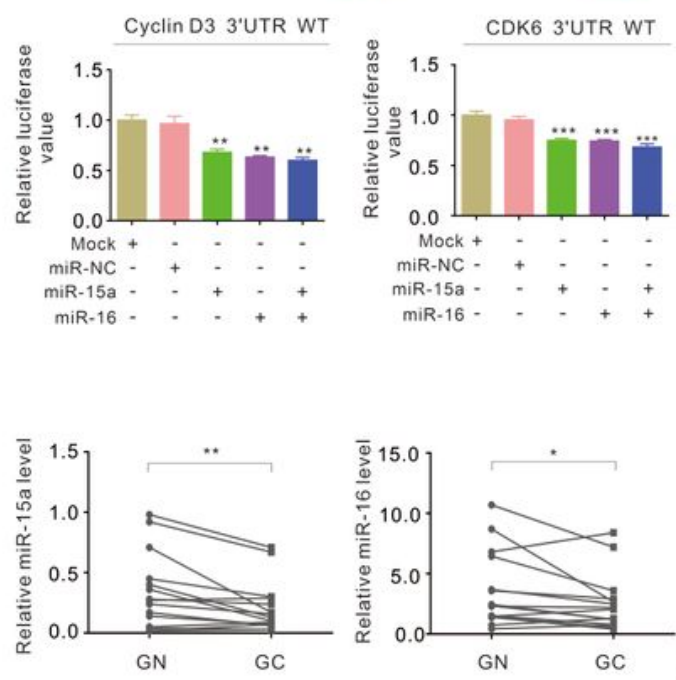

B

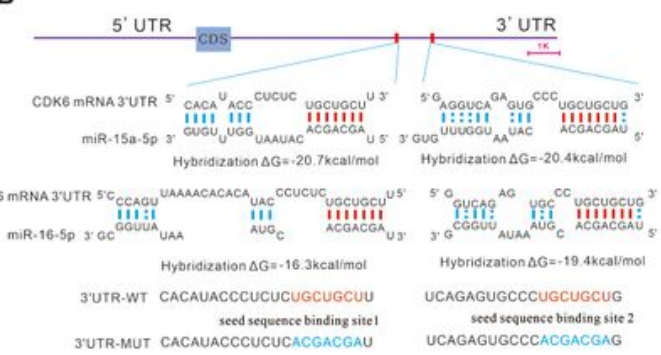

D

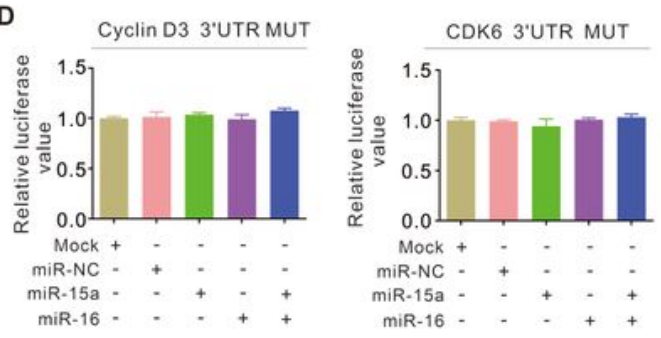

G

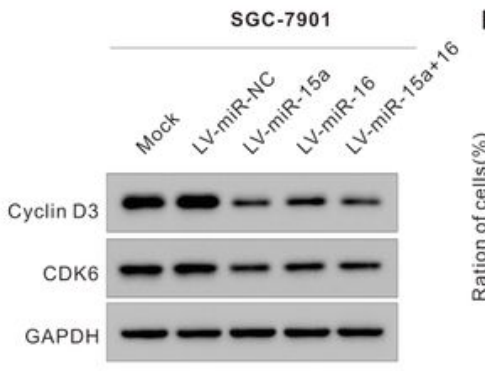

H
$\mathrm{F}$

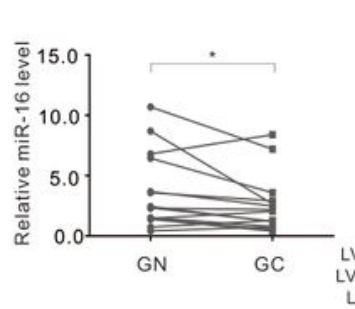

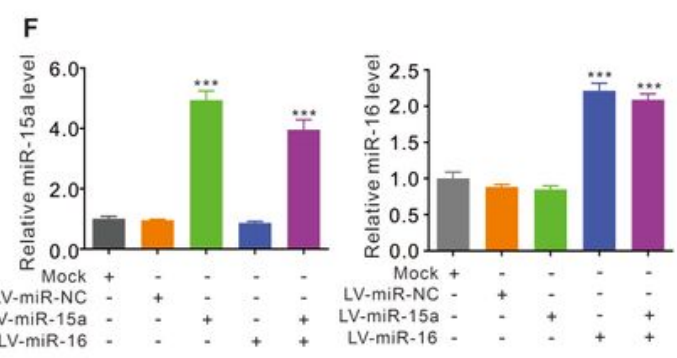
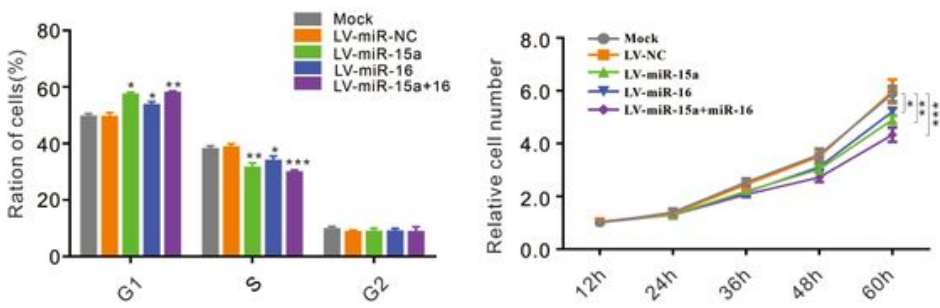

J
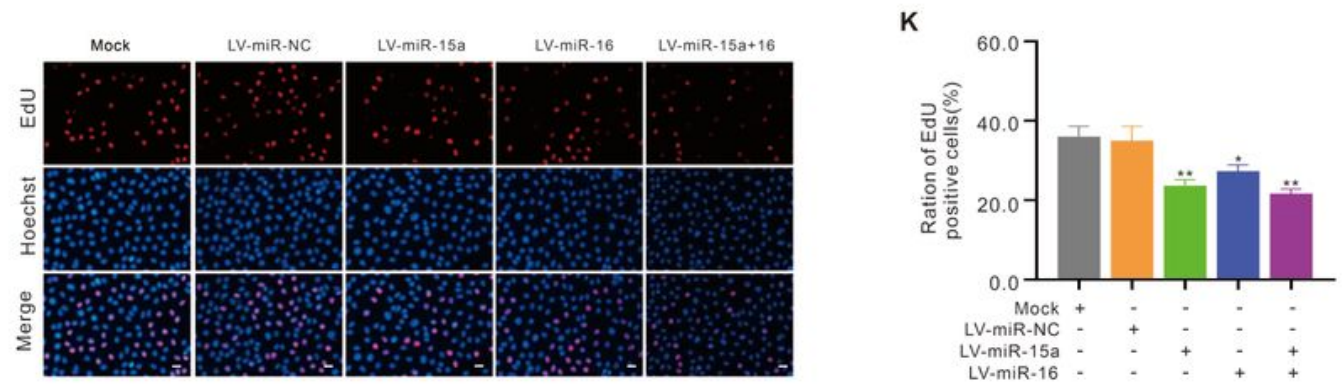

Figure 7 
miR-15a/16 suppressed cell proliferation by targeting Cyclin D3-CDK6 complex (A and B) Schematic description of the hypothesized duplex formed by interaction between the Cyclin D3 or CDK6 3'-UTR binding sites and miR-15a/16. ( $C$ and D) Relative luciferase activities in 293T cells transfected with miR15a and miR-16. (C) Wild-type miR-15a/16 binding sites. (D) Mutant miR-15a/16 binding sites. (E) Quantitative RT-PCR analysis of the expression levels of miR-15a and miR-16 in 15 pairs of gastric cancer tissues pairs. (F) Quantitative RT-PCR analysis of miR-15a and miR-16 levels in the SGC-7901 cells infected with miR-15a and miR-16 overexpression lentivirus. (G) Western blot analysis of Cyclin D3 or CDK6 protein levels in the SGC-7901 cells infected with miR-15a and miR-16 overexpression lentivirus. (H) Cell cycle distribution was analyzed using flow cytometry. (I) Cell proliferation was evaluated by CCK8 assay. ( $\mathrm{J}$ and $\mathrm{K}$ ) Cell proliferation was evaluated by EdU assay. $(\mathrm{J})$ Representative images, Scale bar $=25$ $\mu \mathrm{m}$. (K) Quantitative analysis of EdU-positive cells. ${ }^{*} P<0.05 ;{ }^{*} P<0.01 ; * \star * P<0.001$. 
A

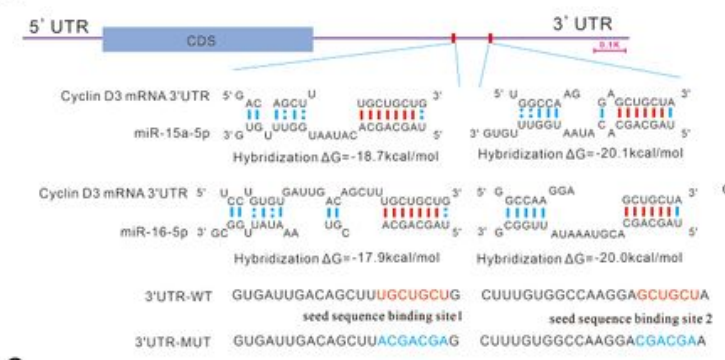

C

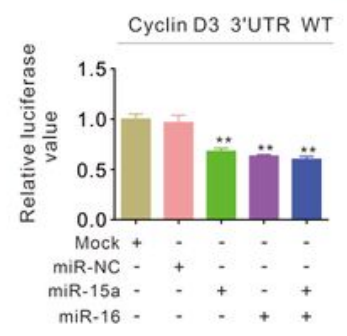

E
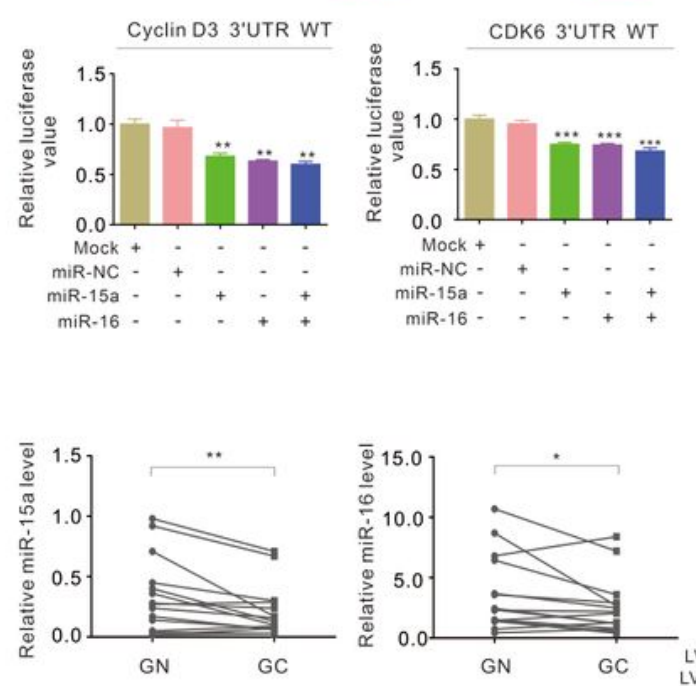

B

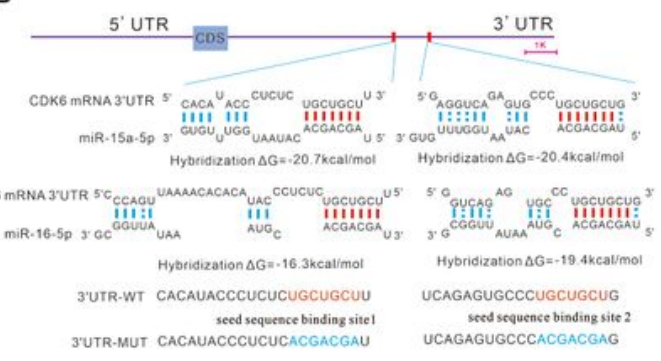

D

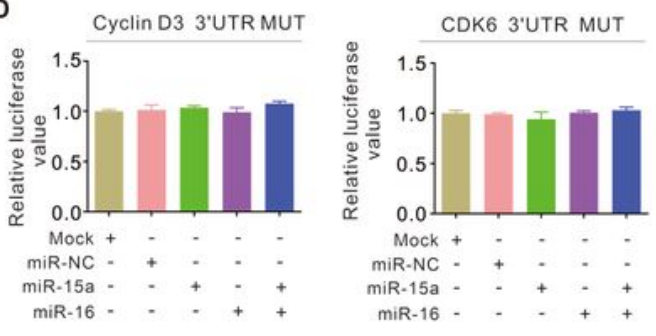

G

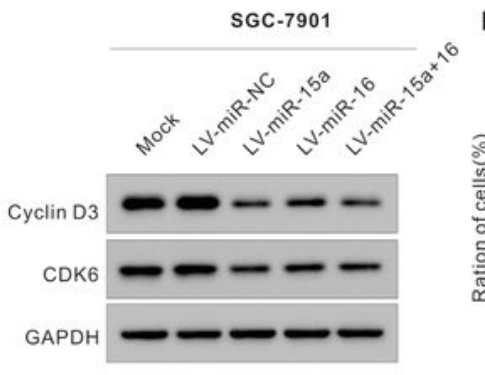

H

$\mathrm{F}$

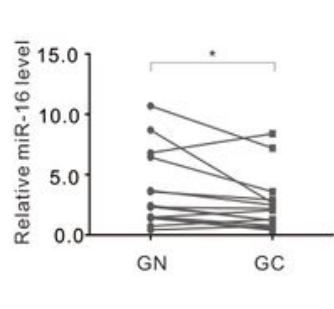

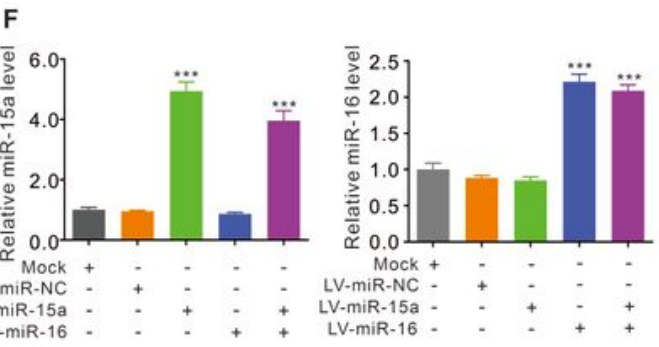
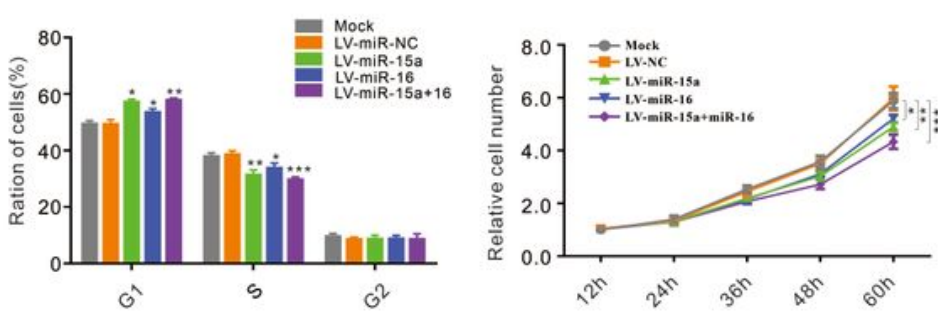

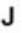
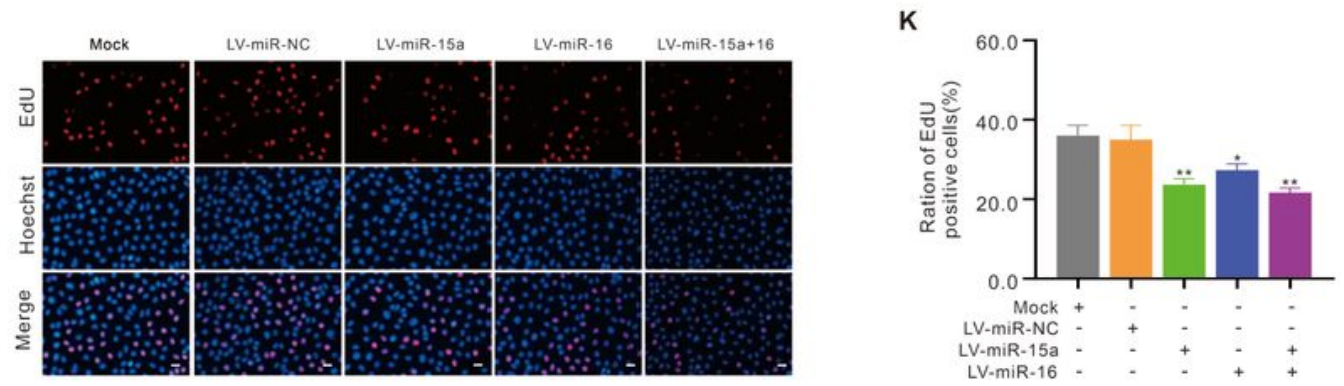

\section{Figure 7}

miR-15a/16 suppressed cell proliferation by targeting Cyclin D3-CDK6 complex (A and B) Schematic description of the hypothesized duplex formed by interaction between the Cyclin D3 or CDK6 3'-UTR binding sites and miR-15a/16. ( $C$ and D) Relative luciferase activities in 293T cells transfected with miR15a and miR-16. (C) Wild-type miR-15a/16 binding sites. (D) Mutant miR-15a/16 binding sites. (E) Quantitative RT-PCR analysis of the expression levels of miR-15a and miR-16 in 15 pairs of gastric cancer 
tissues pairs. (F) Quantitative RT-PCR analysis of miR-15a and miR-16 levels in the SGC-7901 cells infected with miR-15a and miR-16 overexpression lentivirus. (G) Western blot analysis of Cyclin D3 or CDK6 protein levels in the SGC-7901 cells infected with miR-15a and miR-16 overexpression lentivirus. $(H)$ Cell cycle distribution was analyzed using flow cytometry. (I) Cell proliferation was evaluated by CCK8 assay. ( $\mathrm{J}$ and $\mathrm{K}$ ) Cell proliferation was evaluated by EdU assay. $(\mathrm{J})$ Representative images, Scale bar $=25$ $\mu \mathrm{m}$. (K) Quantitative analysis of EdU-positive cells. ${ }^{*} \mathrm{P}<0.05 ;{ }^{*} \mathrm{P}<0.01 ; * \star * \mathrm{P}<0.001$.

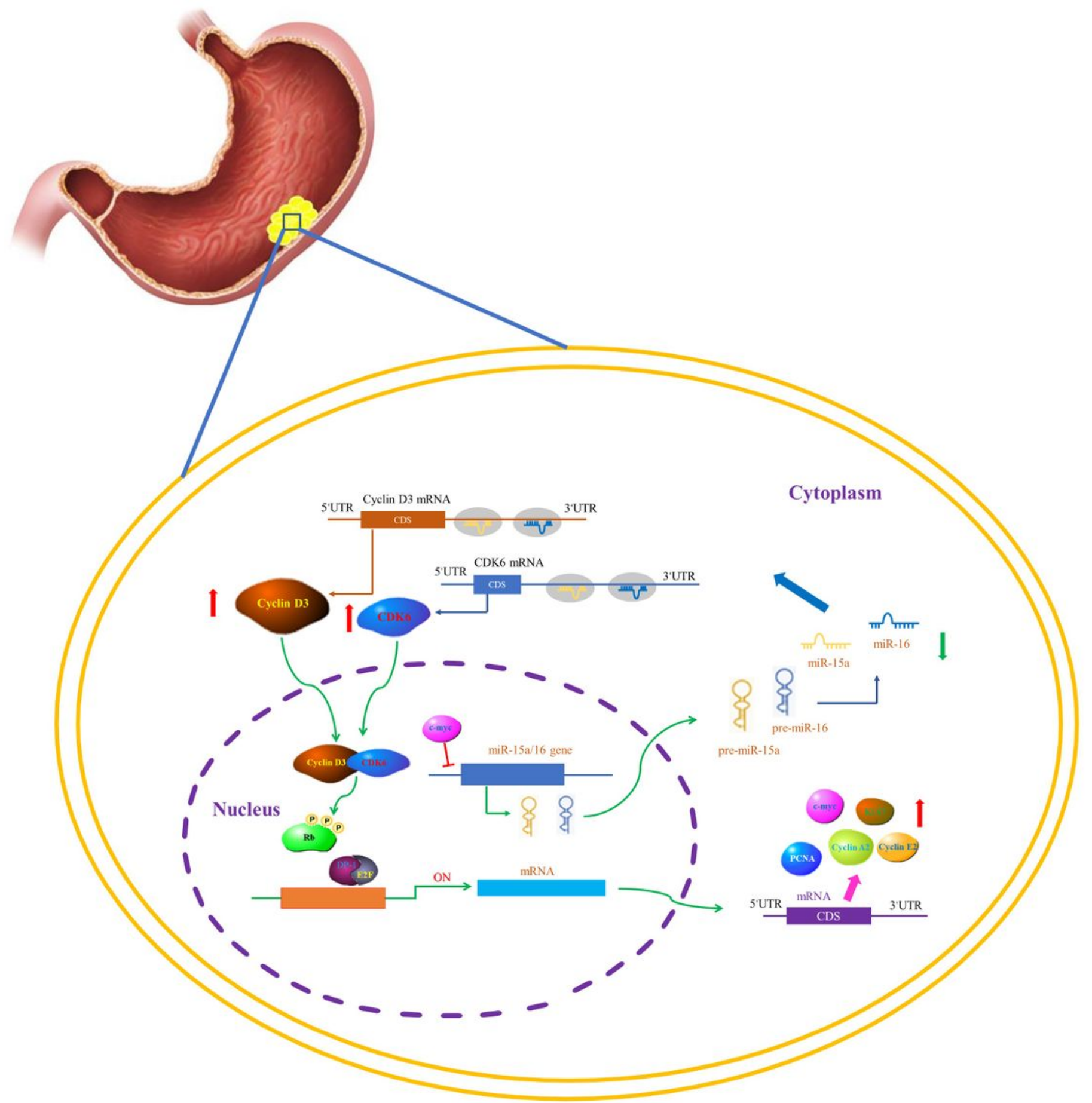

Figure 8 
Working model of Cyclin D3-CDK6/c-Myc/miR-15a/16 feedback loop axis in gastric cancer

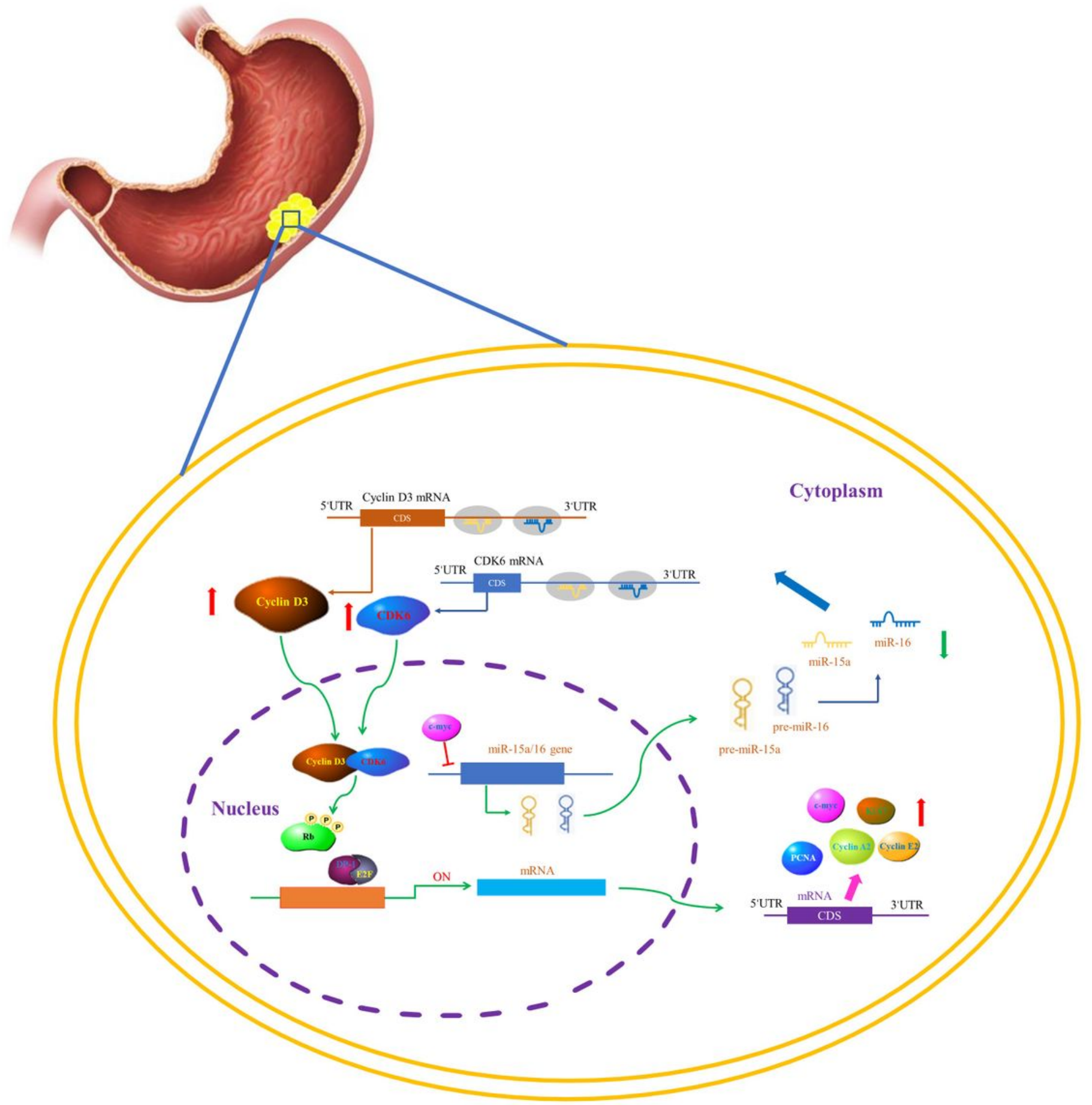

Figure 8

Working model of Cyclin D3-CDK6/c-Myc/miR-15a/16 feedback loop axis in gastric cancer

\section{Supplementary Files}

This is a list of supplementary files associated with this preprint. Click to download. 
- SupplementaryTable3.docx

- SupplementaryTable3.docx

- supplementaryfigurelegends.docx

- supplementaryfigurelegends.docx

- supplementaryfigure11.jpg

- supplementaryfigure11.jpg

- supplementaryfigure2.jpg

- supplementaryfigure2.jpg

- supplementaryfigure3.jpg

- supplementaryfigure3.jpg

- supplementaryfigure4.jpg

- supplementaryfigure4.jpg

- supplementaryfigure5.jpg

- supplementaryfigure5.jpg

- supplementaryfigure6.jpg

- supplementaryfigure6.jpg

- supplementaryfigure8.jpg

- supplementaryfigure8.jpg

- supplementarytable1.docx

- supplementarytable1.docx

- supplementarytable2.xlsx

- supplementarytable2.xlsx

- supplementaryfigure7.jpg

- supplementaryfigure7.jpg

- supplementaryfigure9.jpg

- supplementaryfigure9.jpg 